التحليل القياسى والتتبؤ المستقبلى للعوامل الاقتصادية المؤثرة على صادرات الفراولة طارق على أحمد عبدالله

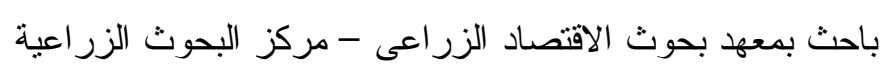

Received on: $2 / 7 / 2017$ Accepted for publication on: 12/7/2017

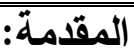

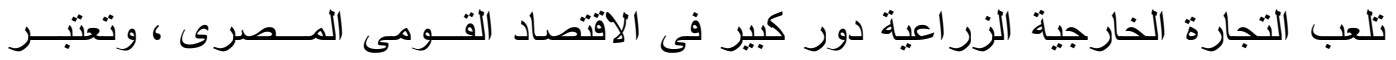

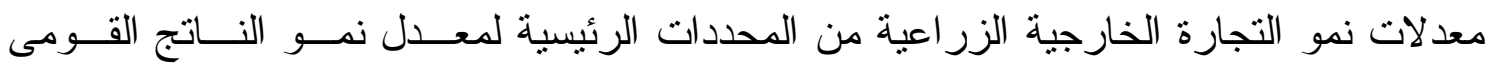

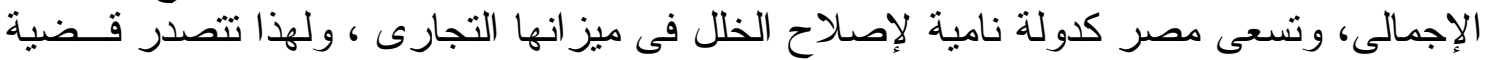

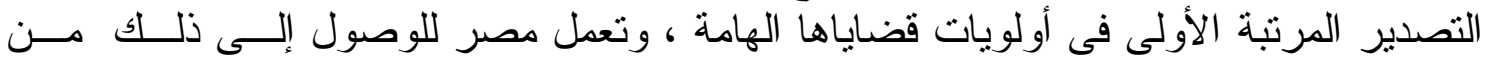

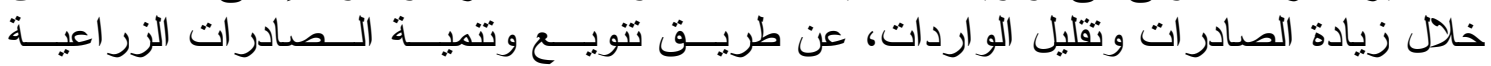

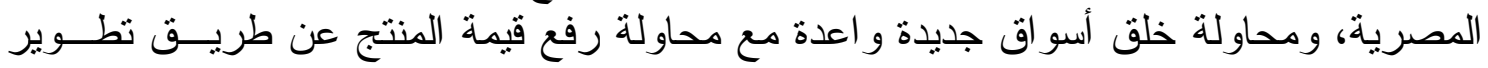
وزيادة الكفاءة التصديرية، ولتمية التئة القدرة التتافسية.

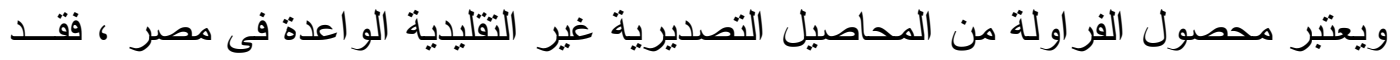

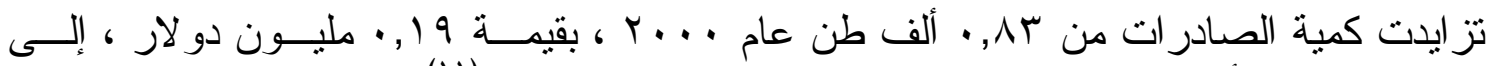

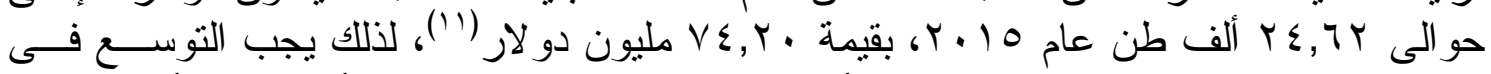

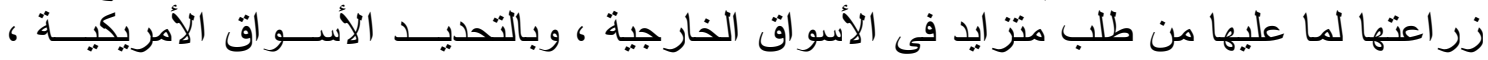

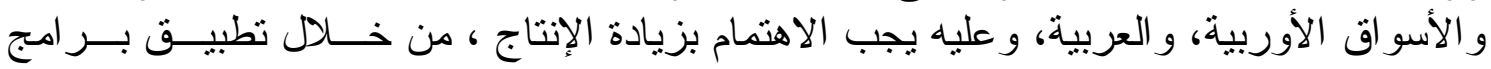

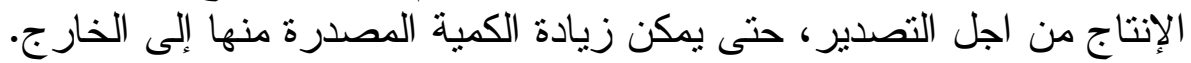

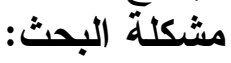

بالرغم من أن مصر تمتلك كثير آ من المقومات و العو امل التى تساعد على تطور تجارتهــا

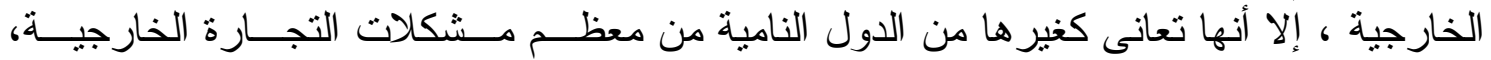

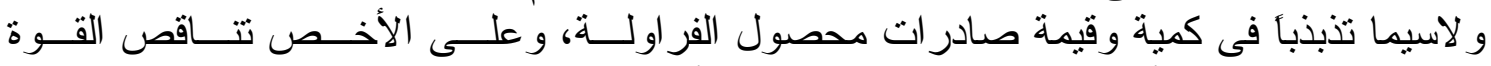

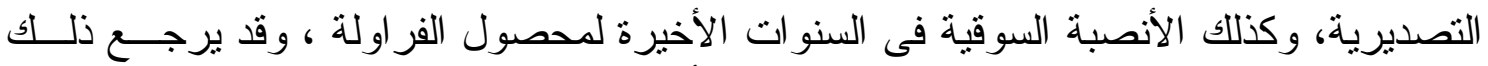

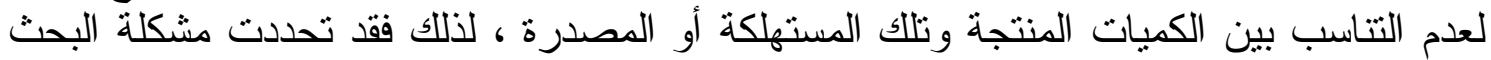
فى التعرف على أهم المتغير ات الاقتصادية المحلية المؤثرة على الكميات المصدرة من محصول

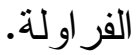

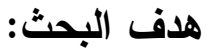

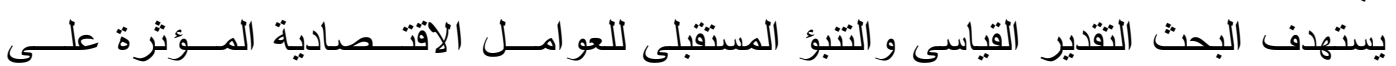

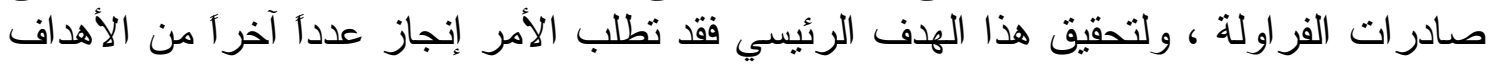

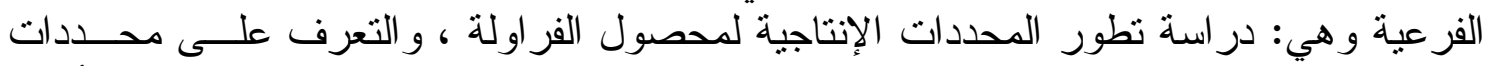

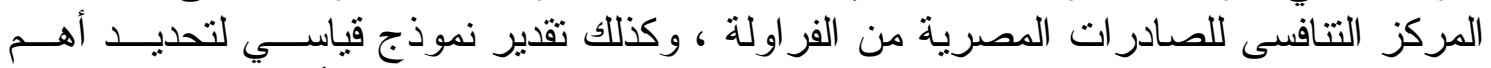

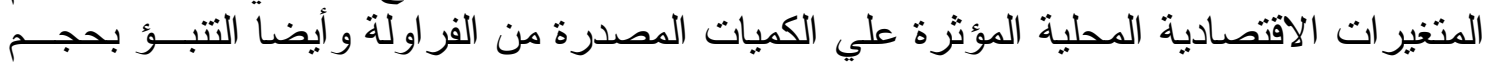

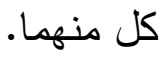

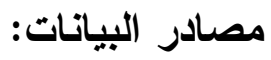

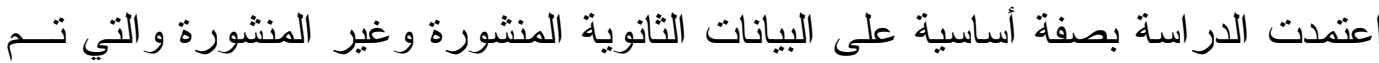

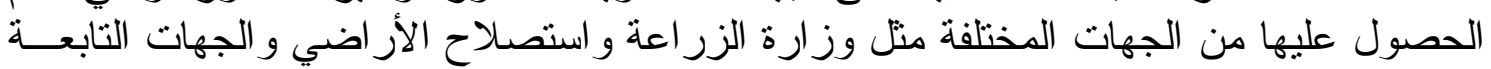

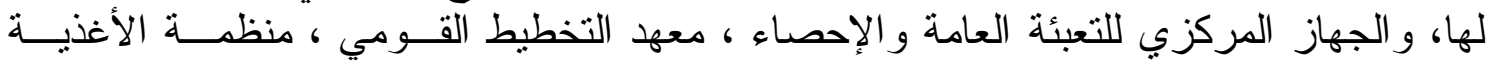

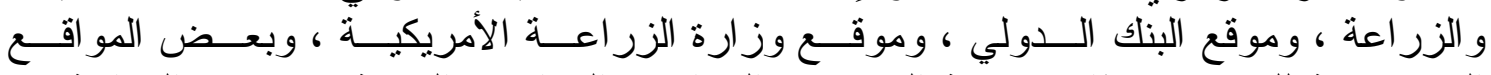
المتخصصة للبيانات ، هذا بالإضافة إلى بعض المر اجع و الدر اسات المعنية بموضو ع الدر الدر اسة . 


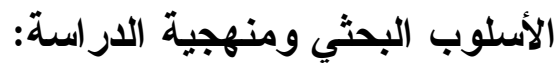

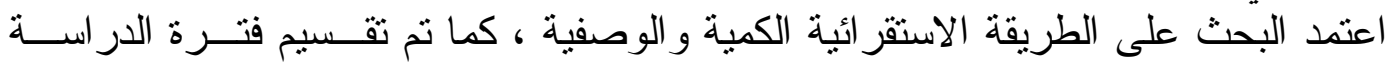

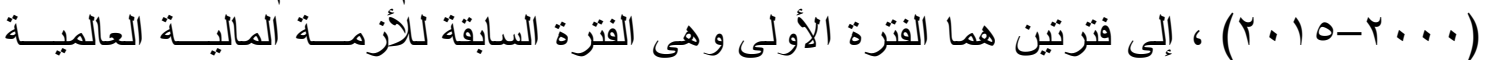

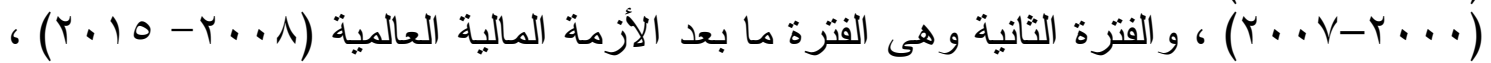
باستخدام اختبار تشاو (Chow) لقياس أثز التغير ات الاقتصادية على المتغير ات محل الدر اســة ،

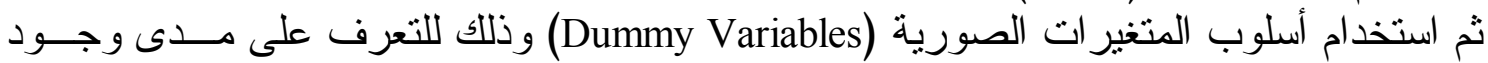

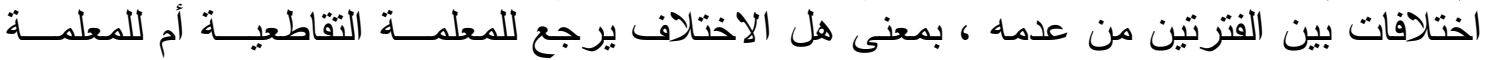
الانحدارية أو كلاهما معاً.

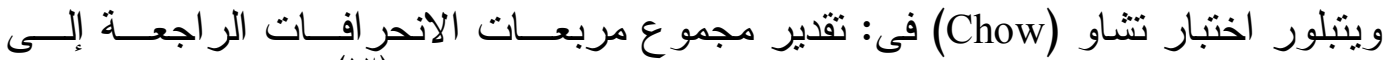

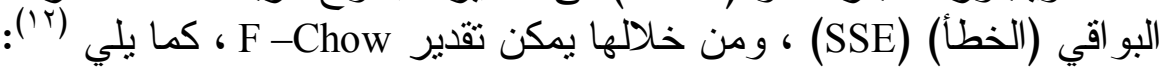

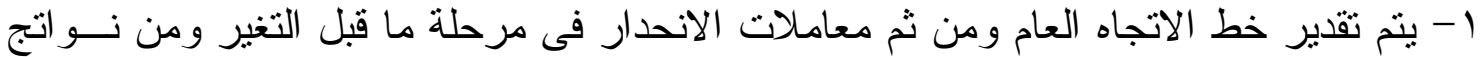

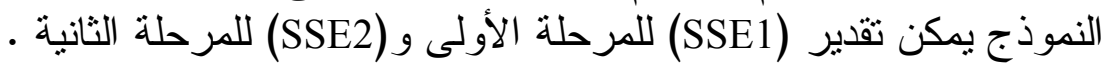

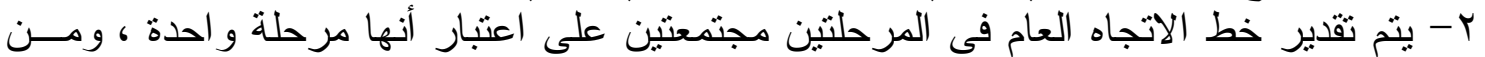

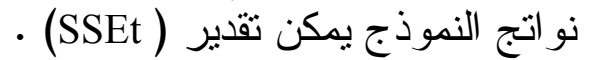

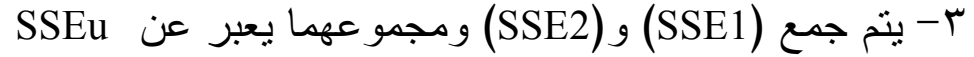
ع - يحسب الفرق بين التقديرين SSEt و وSSEu و $\mathrm{D}=\mathrm{SSEt}-\mathrm{SSEu}$

$F_{\text {Chow }}=\frac{D}{K} \div \frac{\text { SSEU }}{(\mathrm{N}-2 \mathrm{~K})}$

حيث = K = عدد المتغير ات موضع الدر اسة. N

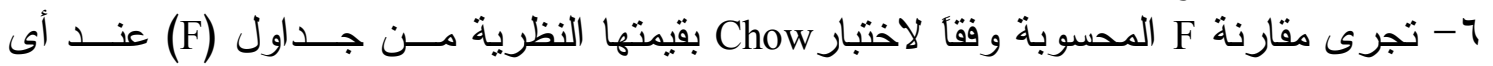

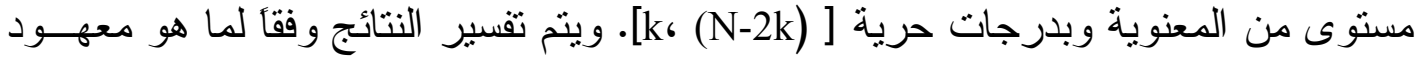

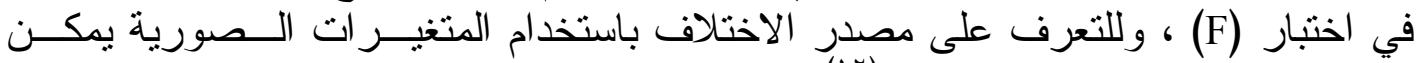

$$
\hat{\mathbf{Y}}_{\mathbf{t}}=\mathbf{a}+\mathbf{b}_{1} \mathbf{X}+\mathbf{b}_{2} \mathbf{X}+\mathbf{b}_{3} \mathbf{X D}
$$

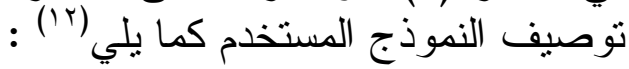

$$
\begin{aligned}
\text { حيث: } & \hat{Y}_{t} \\
\text { المتغير التابع } & =X
\end{aligned}
$$

م متغير انتقالي يأخذ القيمة (صفر) للفترة الأولى و القيمة (الو احد الصحيح) للفترة الثانية D

$\mathrm{D} * \mathrm{X}=\mathrm{XD}$

$$
\hat{\mathbf{Y}}_{\mathbf{t}}=\mathbf{a}+\mathbf{b}_{\mathbf{1}} \mathbf{X}
$$

ومن هذه المعادلة يمكن اشتقاق المعادلة الممثلة للفتزة الأولى كالتالي:

$$
\hat{\mathbf{Y}}_{\mathbf{t}}=\left(\mathbf{a}+\mathbf{b}_{2}\right)+\left(\mathbf{b}_{1}+\mathbf{b}_{3}\right) \mathbf{X}
$$

كما يمكن اشتقاق المعادلة الممنتة للفترة الثانية كالتالي:

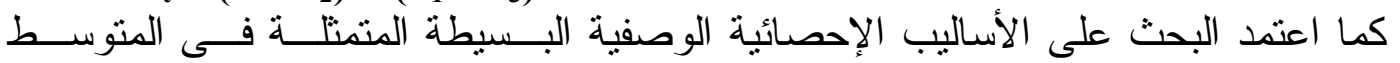

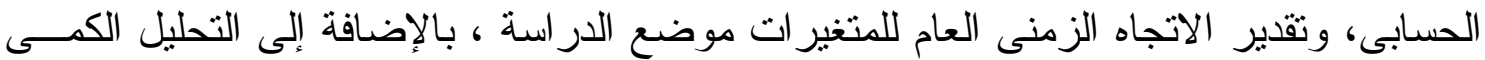

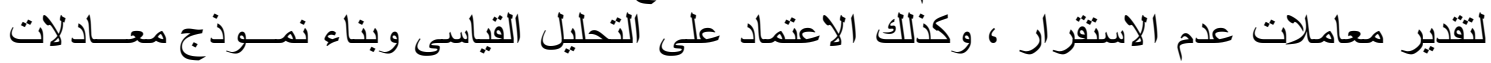

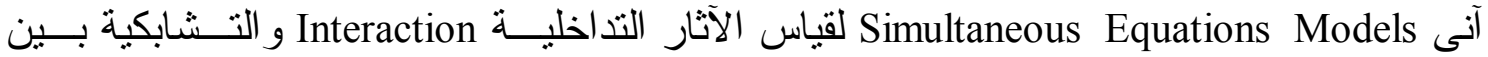

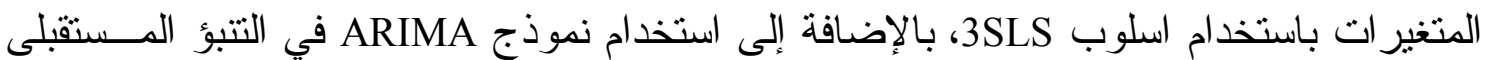
للمتغير ات الهيكلية للنموذج القياسئ. 


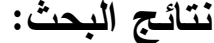 \\ أولاً: تطور المحددات الإنتاجية لمحاصيل الدراسة:

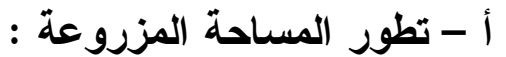

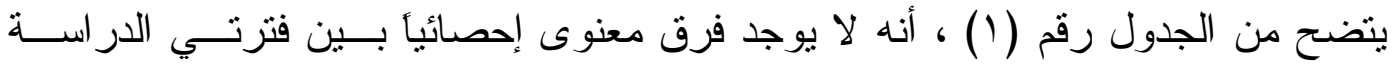

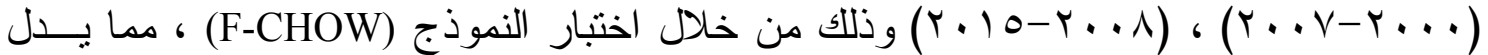

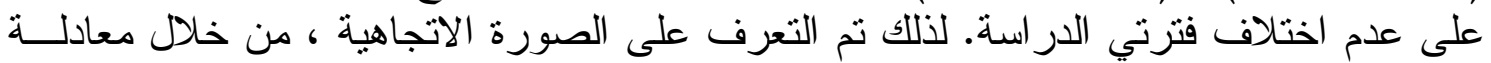

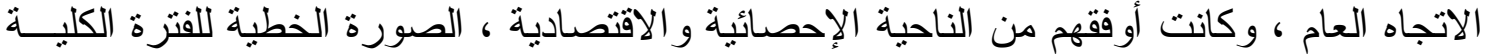

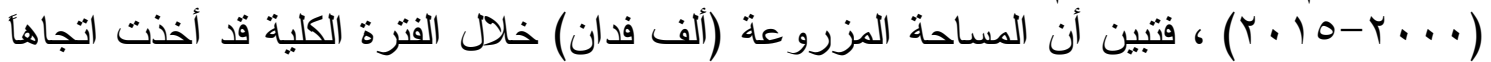

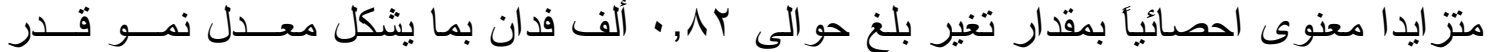

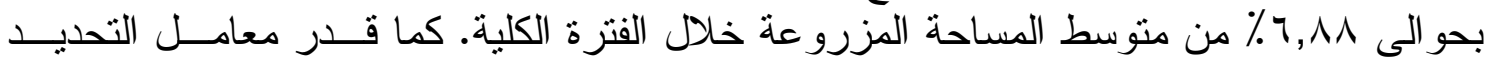

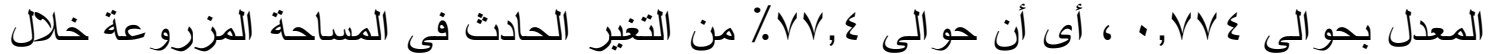

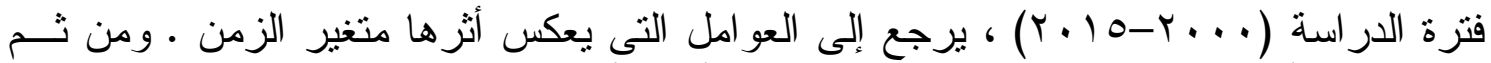

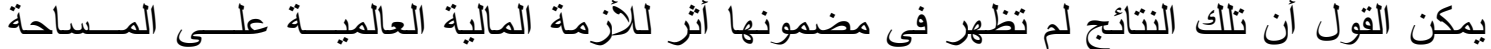

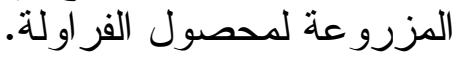

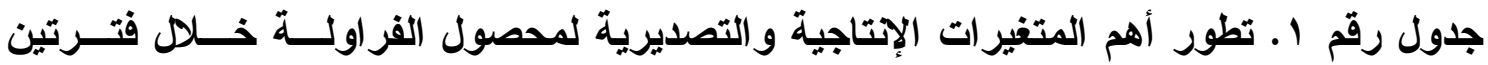

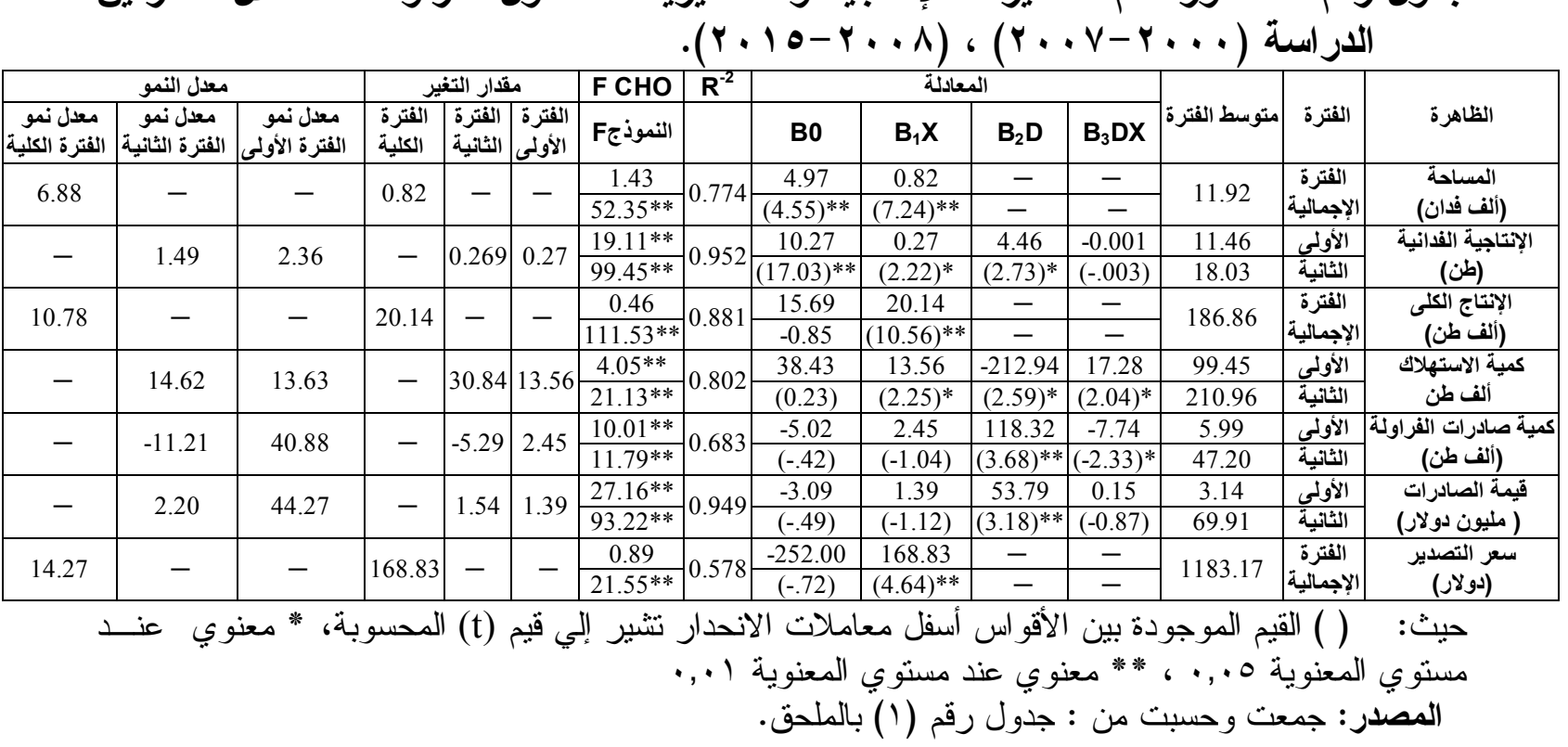

\section{ب - تطور الإنتاجية الفدانية :}

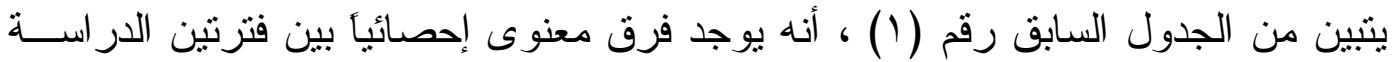

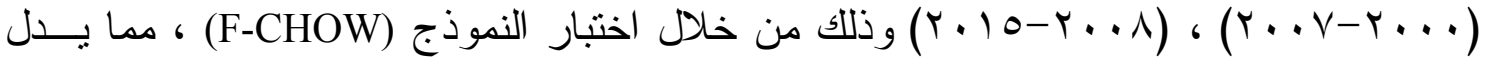

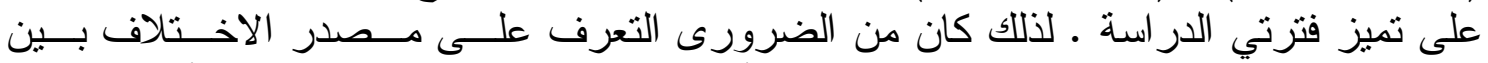

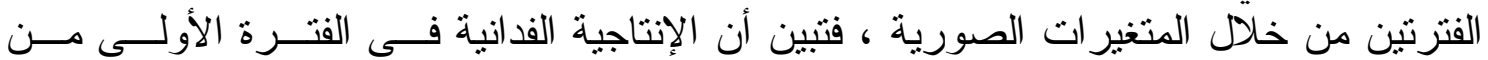

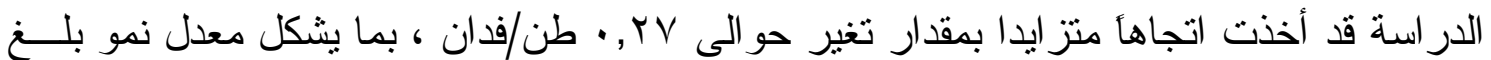

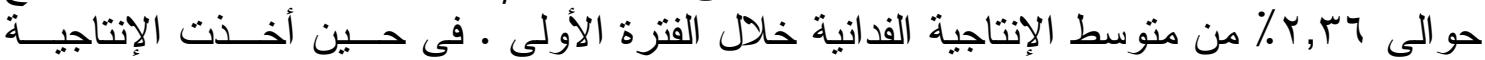

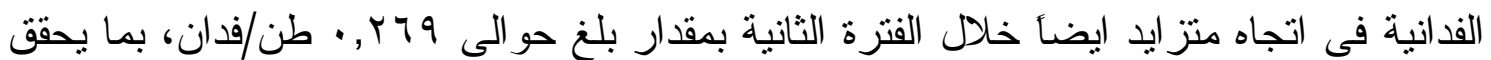

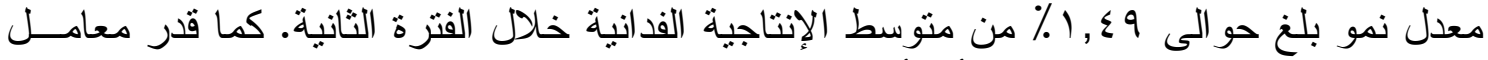

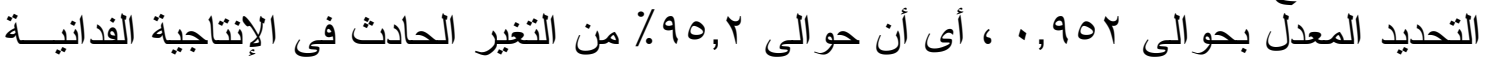

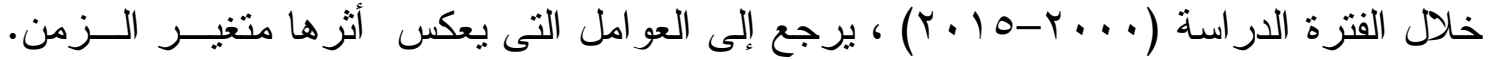




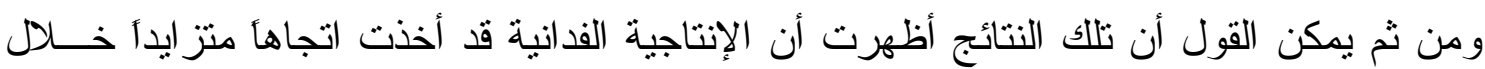

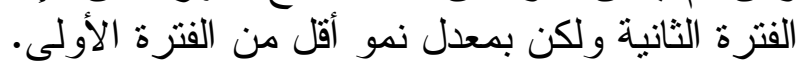

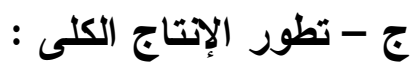

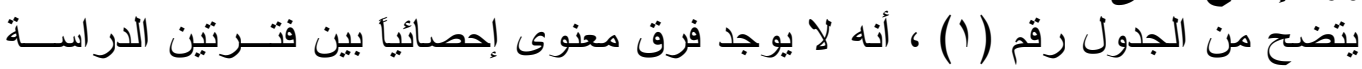

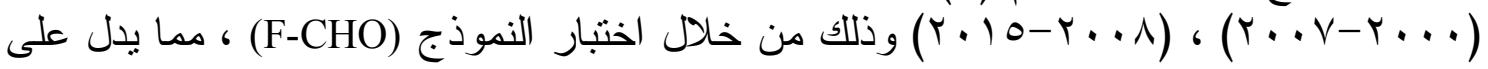

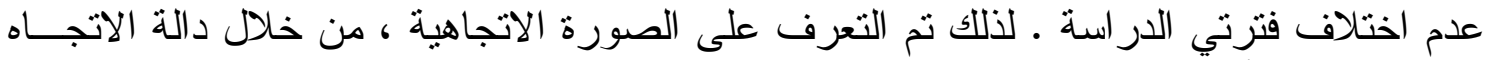

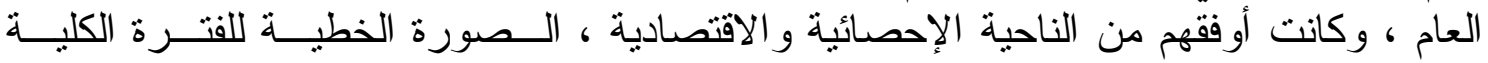

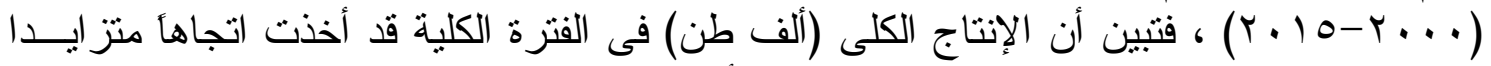

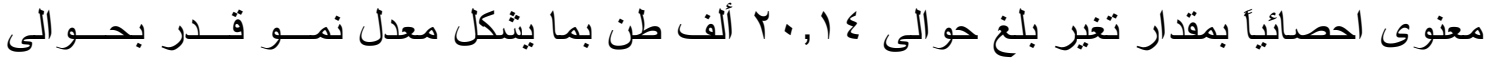

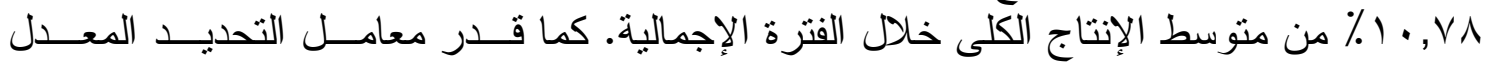

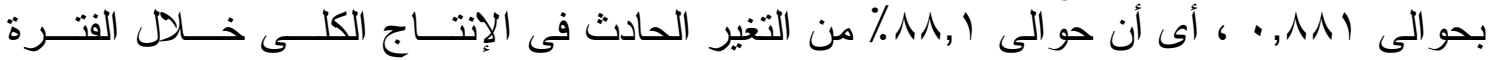

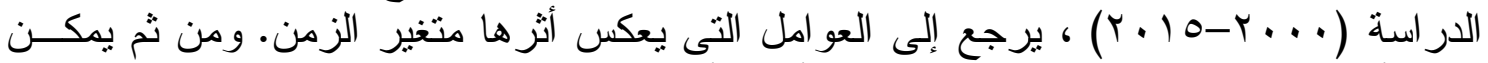

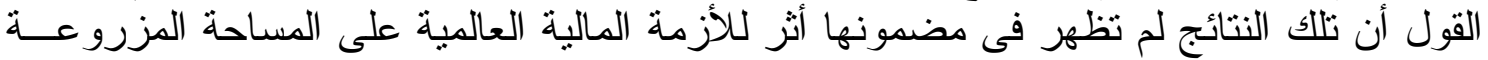

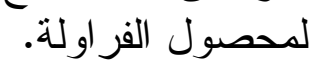
د - نطور كمية استهلاك الفراولة :

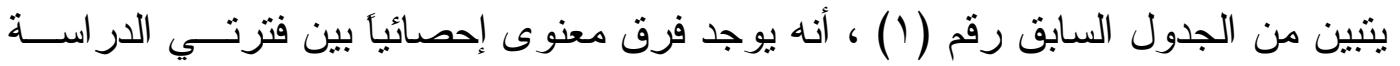

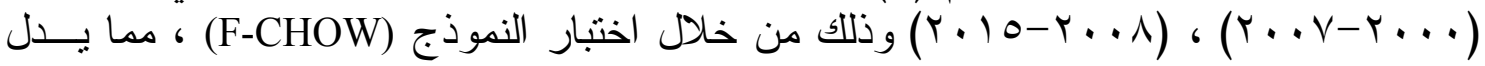

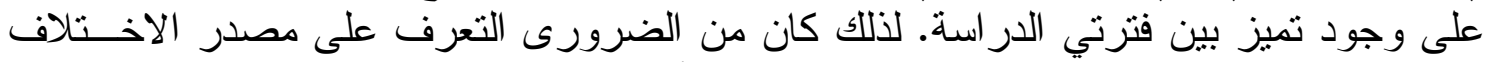

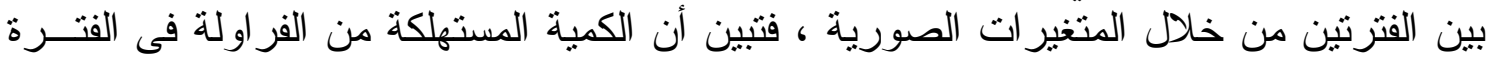

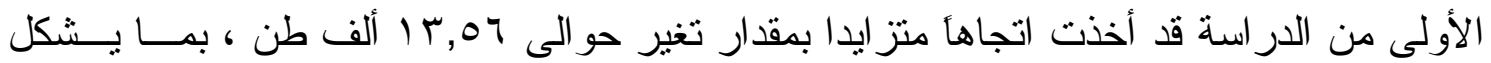

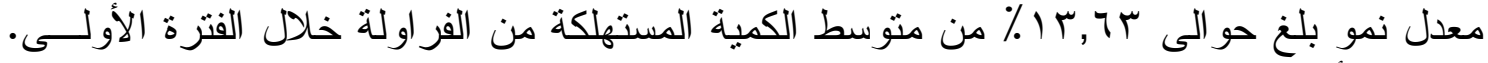

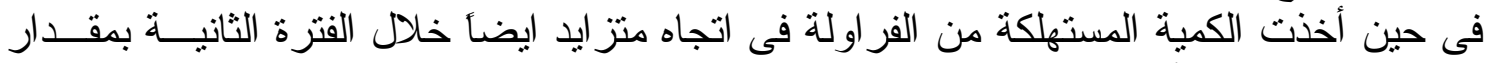

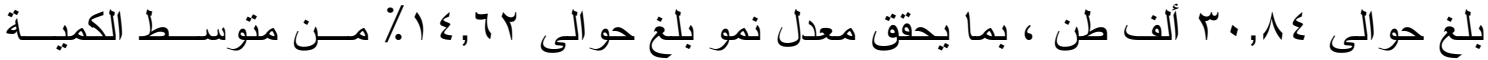

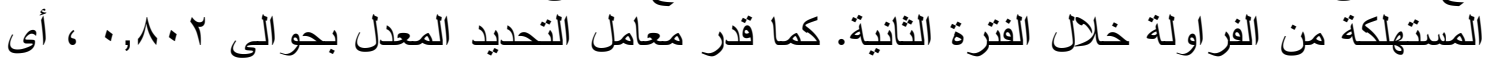

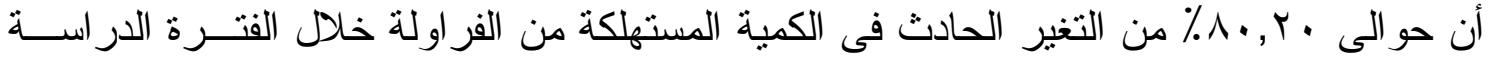

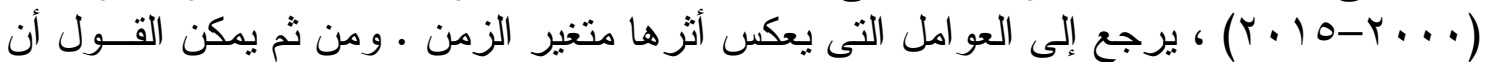

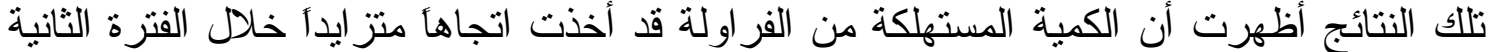
ولكن بمعدل نمو أكبر من الفترة الأولى.

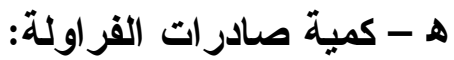

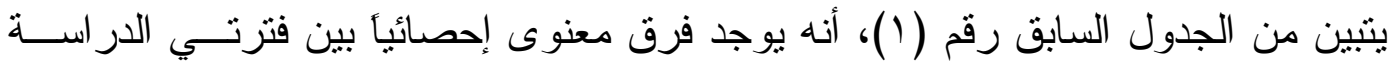

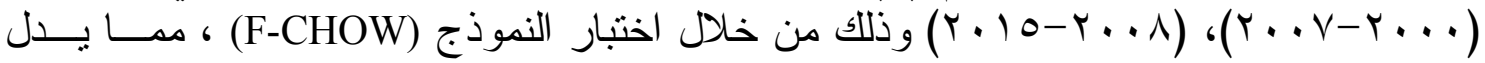

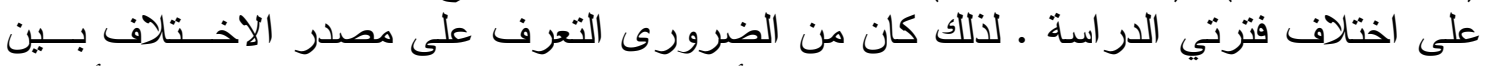

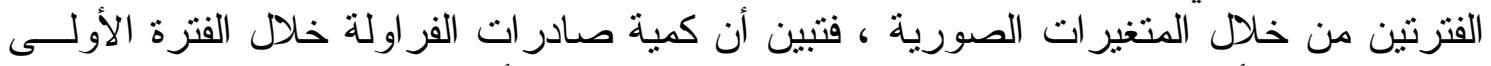

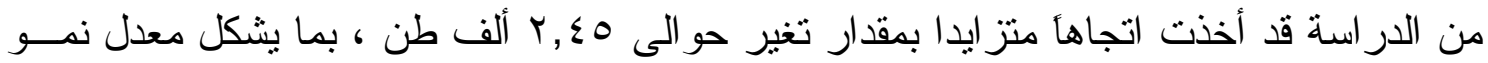

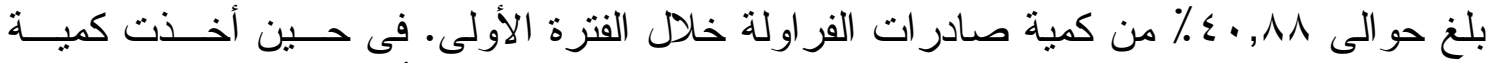

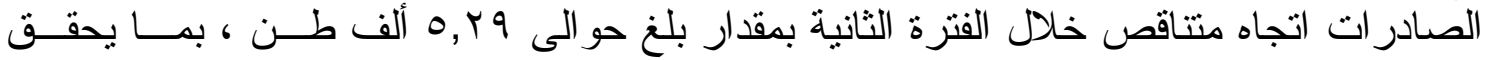

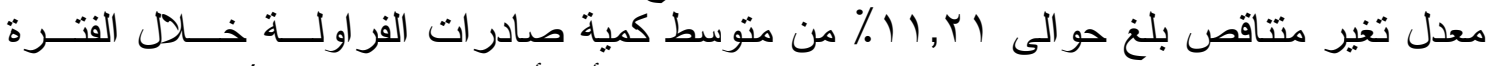

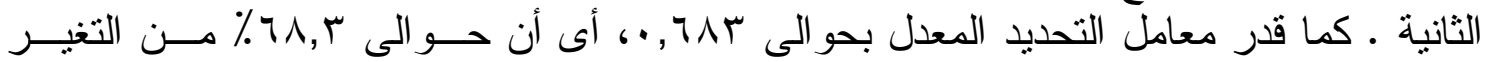

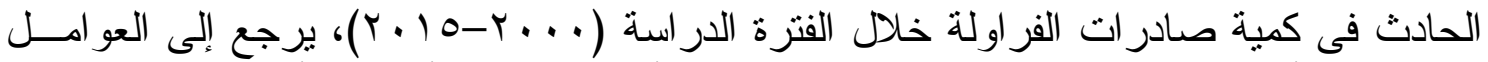

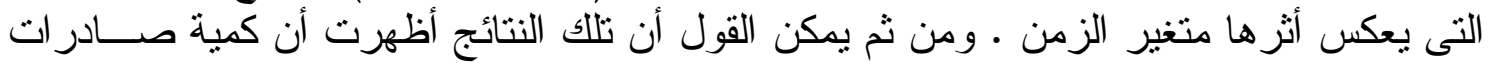


الفراولة قد أخذت اتجاهأ متتاقصأ خلال الفترة الثانية ، بما ينطوى على التـأثير الـسلبى لأثــر

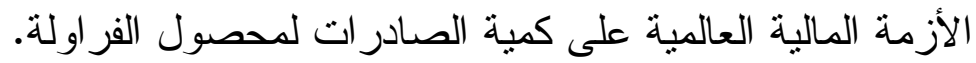
د - ميمة صادرات الفراولة :

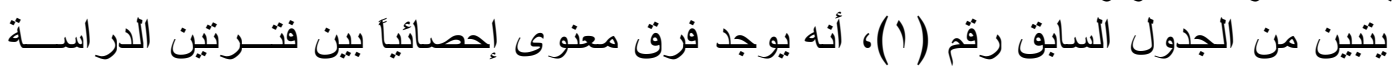

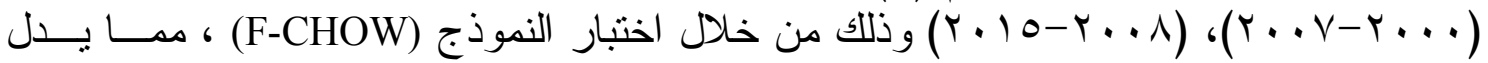

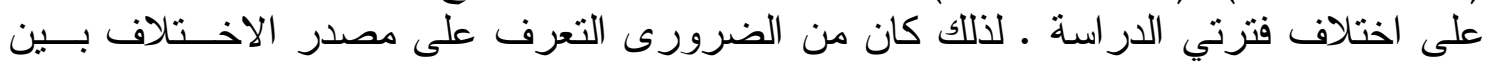

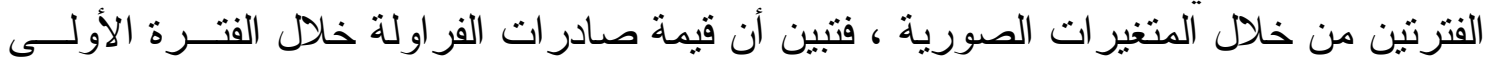

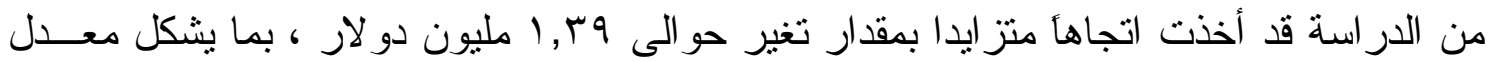

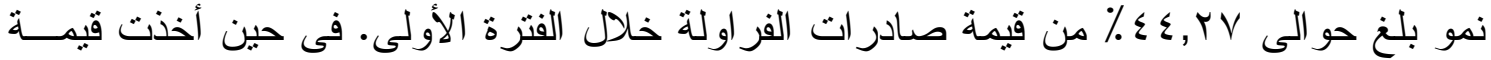

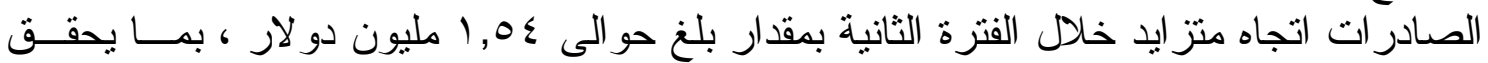

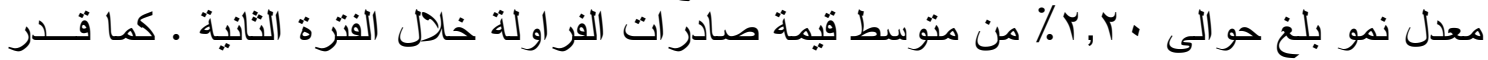

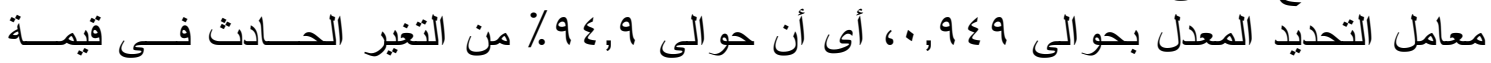

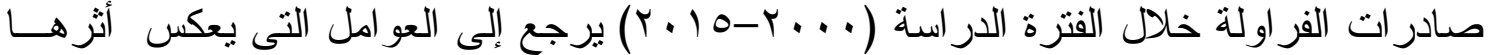

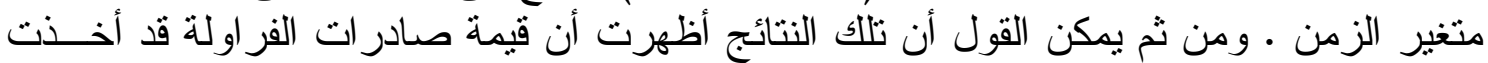

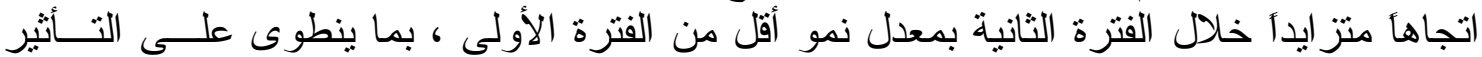
السلبى لأثر الأزمة المالية العالمية على قيمة الصادر اتلية لـعات لمحصول الفراولة.

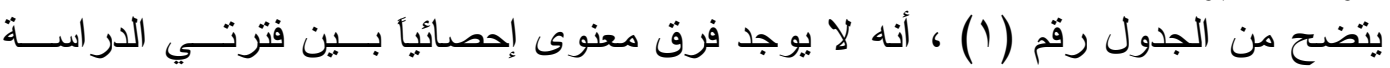

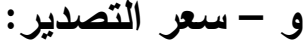

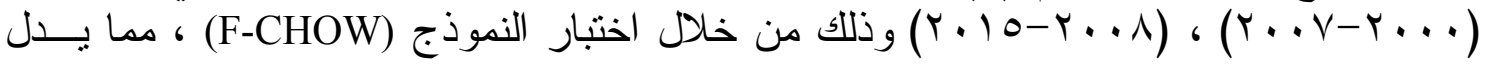

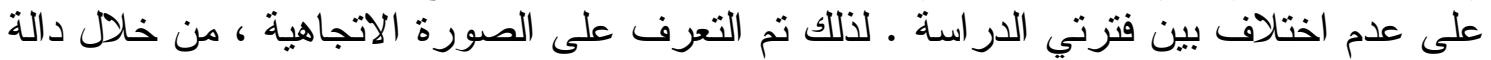

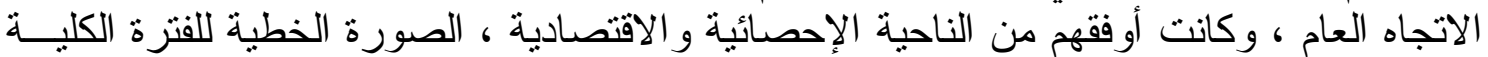

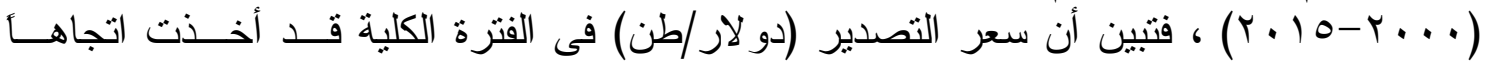

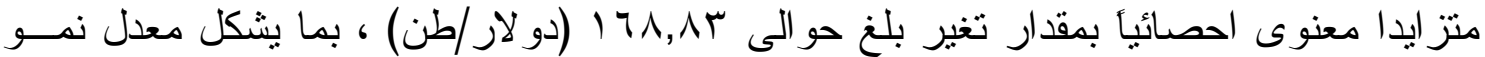

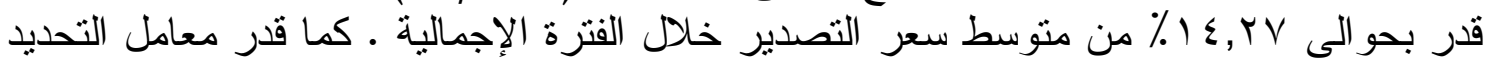

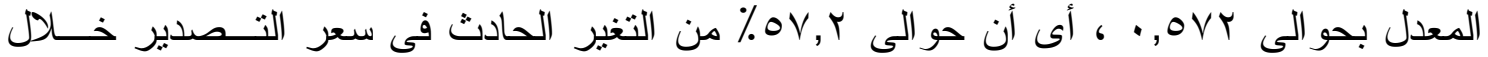

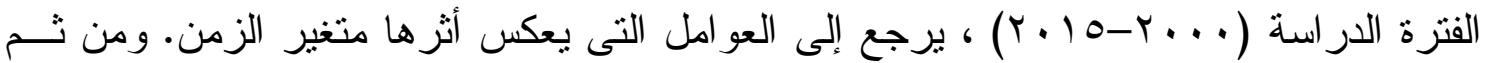
يمكن القول أن تلك النتائج لم تظهر فى مضمونها أثر للأزمة المالية العالمية على سعر التصدير التهدير

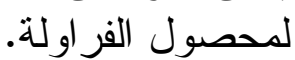
ثانياً - محددات المركز التنافسى للصادرات المصرية من الفراولة: المئية

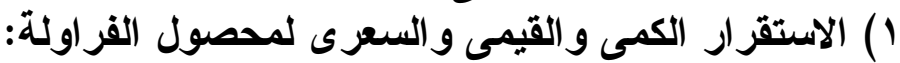

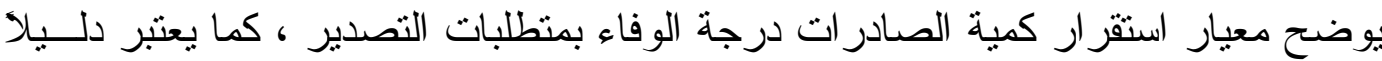

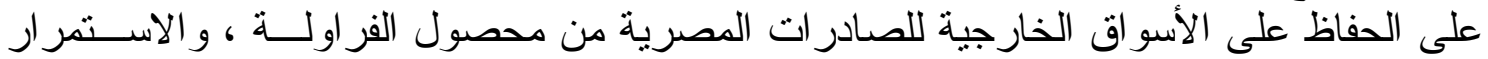

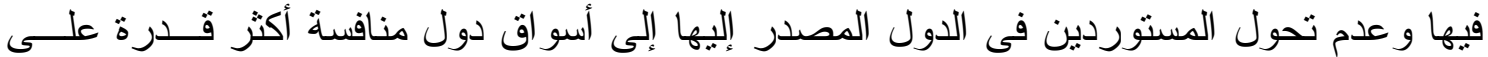

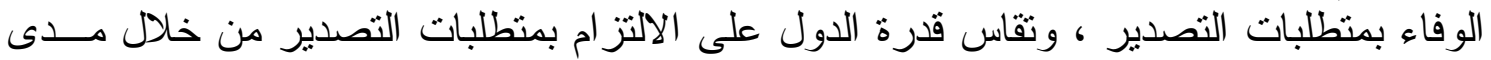

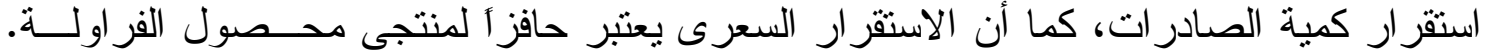

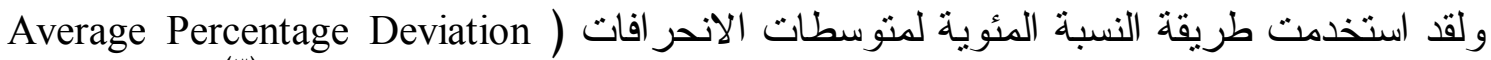
(Method فى حساب معامل عدم الاستقر ار و التى يتم تطبيقها وفقأ للمعادلة التالية("): $\left.\mathbf{S}_{\mathrm{t}}=\frac{\left.\mathbf{Y}_{\mathrm{t}}-\hat{\mathbf{Y}}_{t}\right\rfloor}{\hat{\mathbf{Y}}_{\mathrm{t}}}\right\rfloor * 100$

حيث أن : S S Sتل معامل عدم الاستقر ار الكمى و القيمى و السعرى.

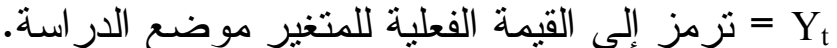

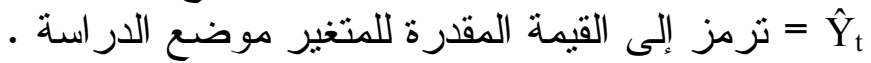




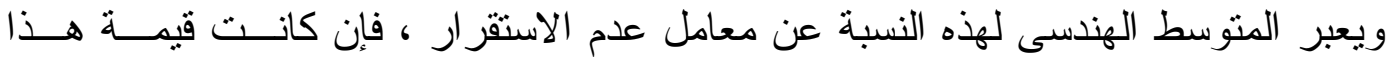

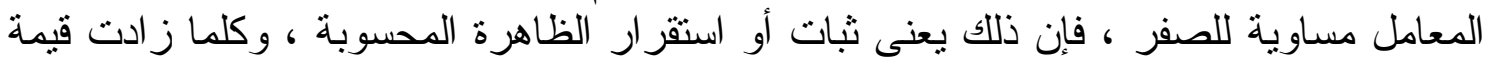

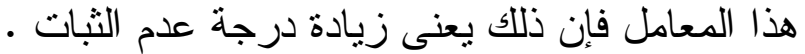

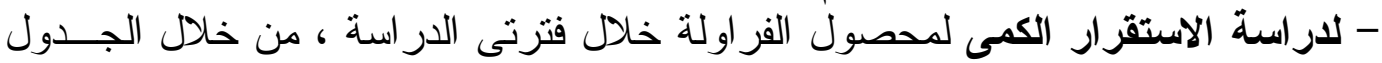

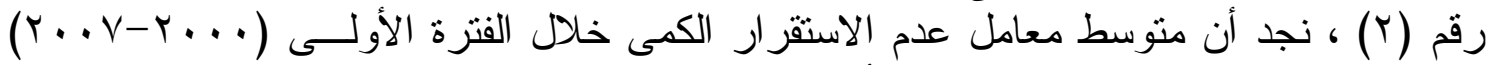

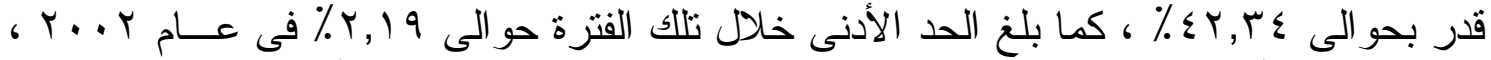

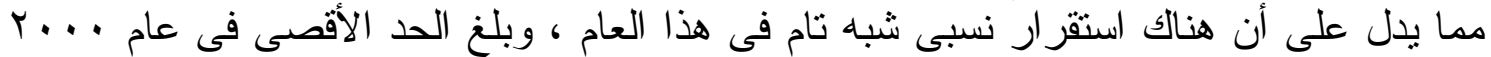

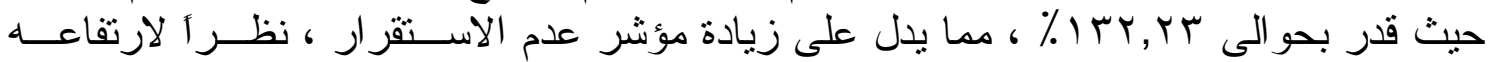

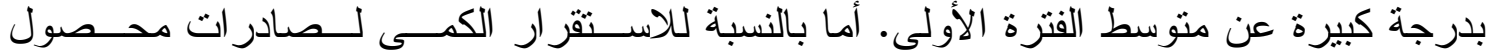

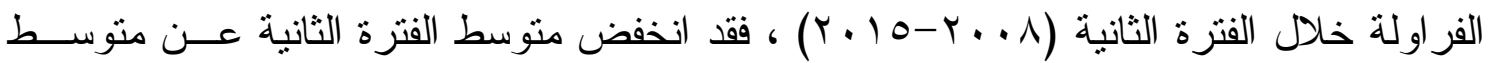

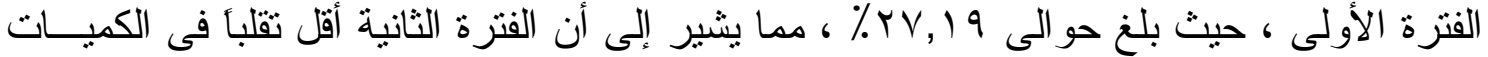

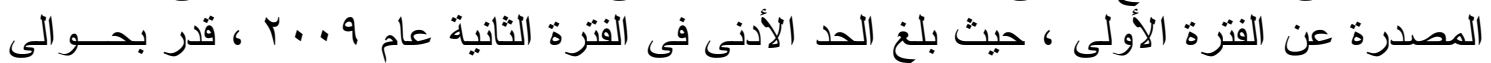

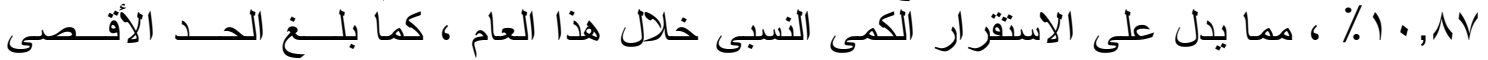

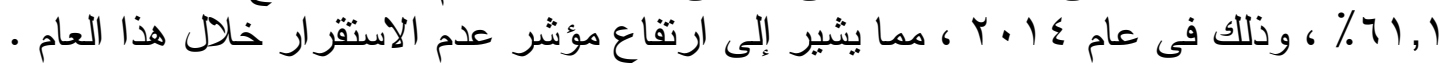

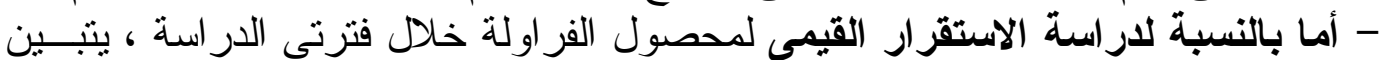

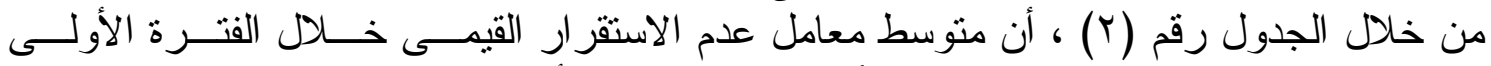

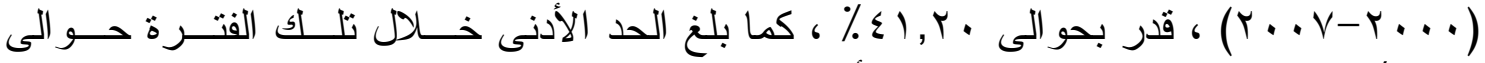

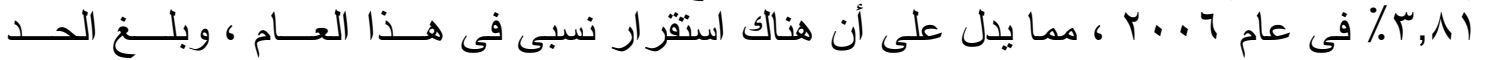

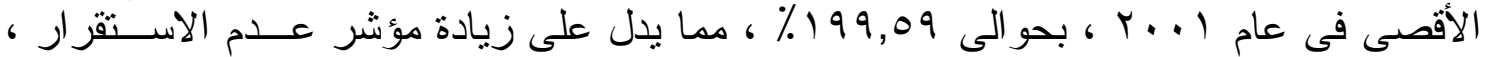

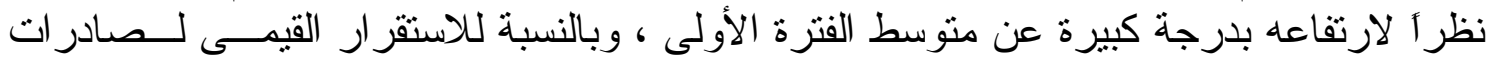

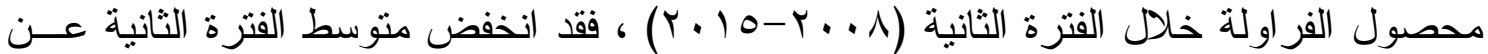

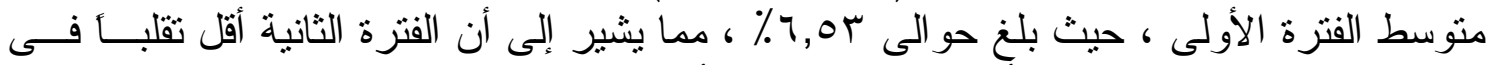

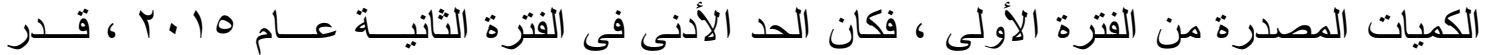

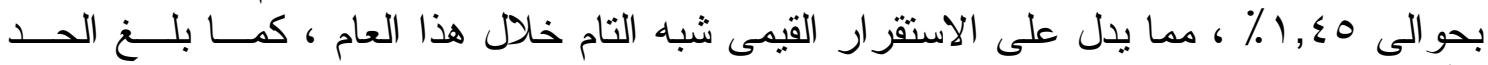

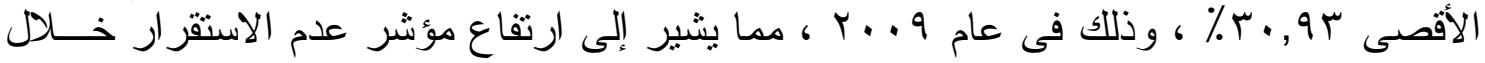

جدول رقم r. تطور معاملات عدم الاستقرار لكميات وقيمة وأسعار التصدير لمحصول الفراولة خــله

\begin{tabular}{|c|c|c|c|}
\hline معامل عدم الاستقز ار للسعر & معامل عدم الاستقرار للقيمة & معامل عدم الاستقر ار للكمية & السنّة \\
\hline 19.13 & 111.14 & 132.23 & 2000 \\
\hline 22.36 & 199.59 & 107.56 & 2001 \\
\hline 2.72 & 16.29 & 2.19 & 2002 \\
\hline 20.95 & 39.94 & 40.86 & 2003 \\
\hline 28.32 & 44.68 & 52.33 & 2004 \\
\hline 7.72 & 66.65 & 68.44 & 2005 \\
\hline 13.49 & 3.81 & 4.69 & 2006 \\
\hline 11.31 & 50.77 & 48.42 & 2007 \\
\hline 13.00 & 41.20 & 42.34 & متوسط هندسى فترة أولى \\
\hline 41.46 & 19.07 & 15.08 & 2008 \\
\hline 7.01 & 30.93 & 10.87 & 2009 \\
\hline 67.26 & 3.13 & 55.55 & 2010 \\
\hline 56.64 & 15.08 & 50.42 & 2011 \\
\hline 66.93 & 9.22 & 48.50 & 2012 \\
\hline 5.92 & 3.79 & 15.44 & 2013 \\
\hline 43.33 & 2.34 & 61.10 & 2014 \\
\hline 14.09 & 1.45 & 14.21 & 2015 \\
\hline 26.82 & 6.53 & 27.19 & متوسط هندسى فترة ثانية \\
\hline
\end{tabular}




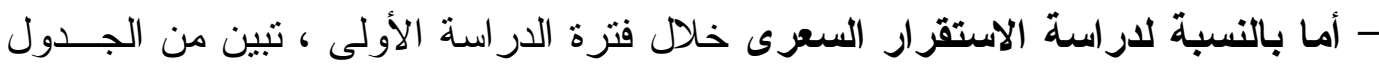

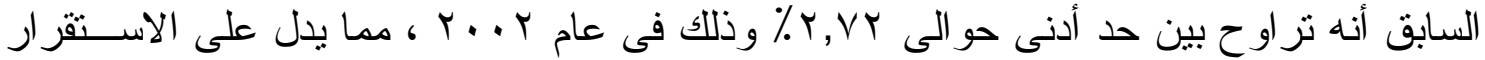

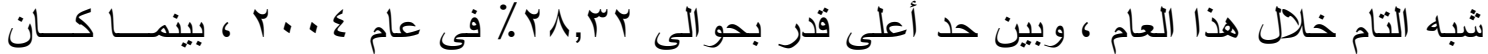

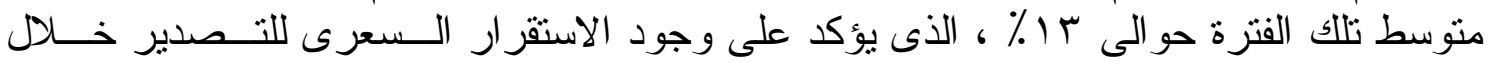

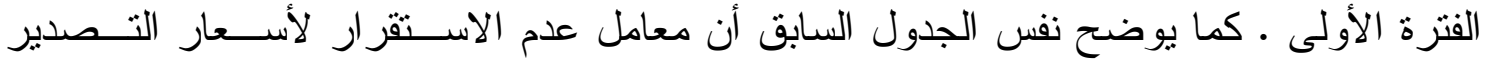

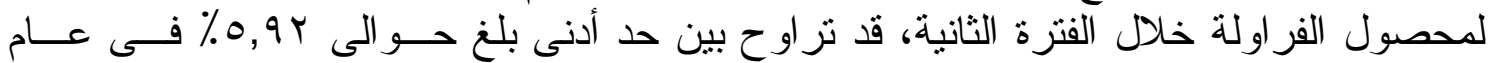

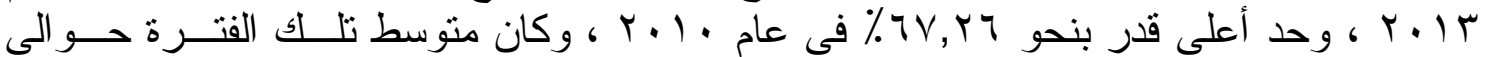

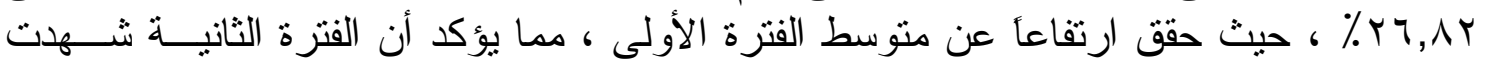

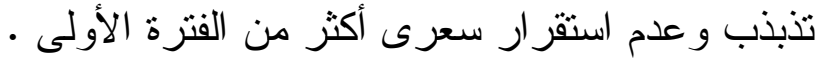

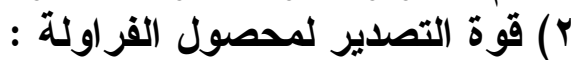

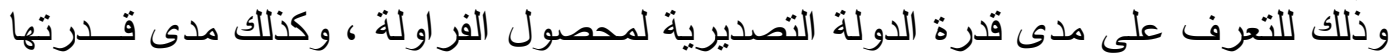

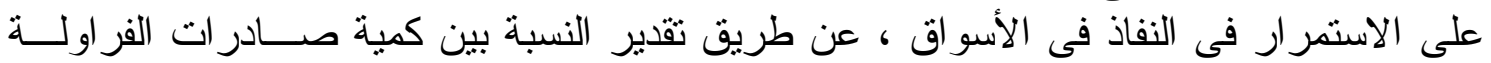

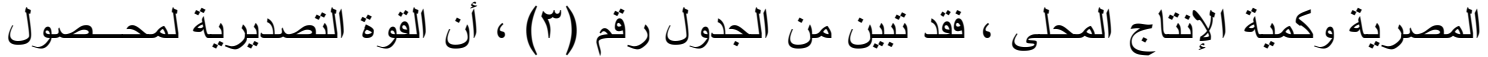

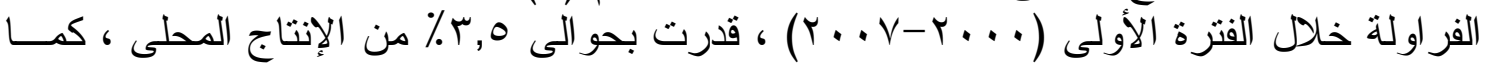

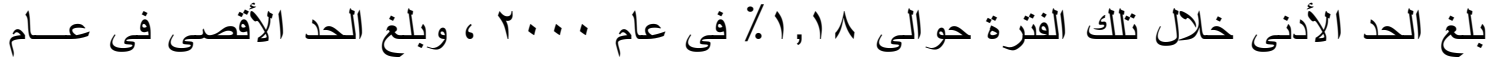

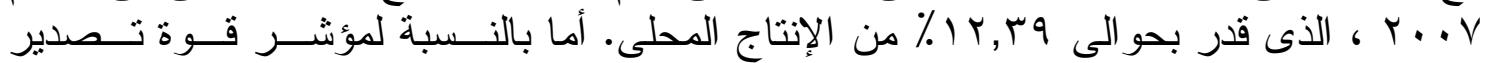

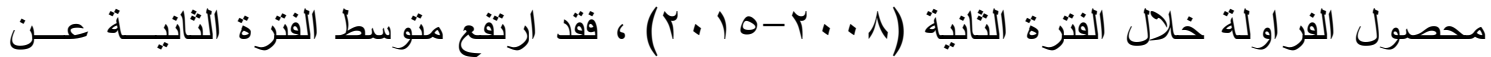

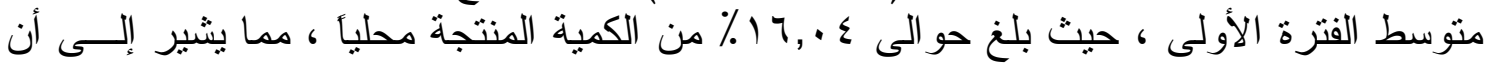

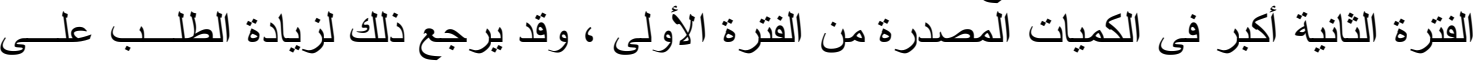

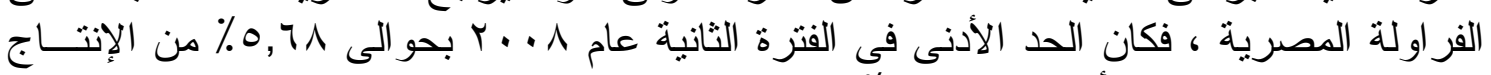

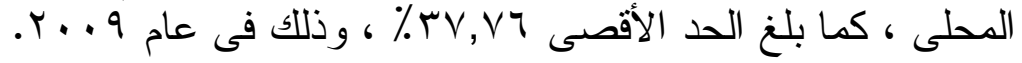

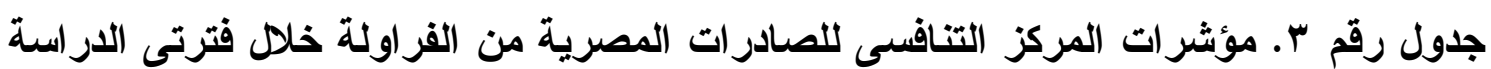

\begin{tabular}{|c|c|c|c|}
\hline الأصبة السوقية & الميزة النسبية & قُوة التصدير & السنوات \\
\hline 0.17 & 4.02 & 1.18 & 2000 \\
\hline 0.25 & 6.21 & 1.82 & 2001 \\
\hline 0.46 & 12.53 & 3.78 & 2002 \\
\hline 0.55 & 17.02 & 3.54 & 2003 \\
\hline 0.59 & 16.46 & 3.28 & 2004 \\
\hline 0.49 & 15.24 & 1.94 & 2005 \\
\hline 1.93 & 65.24 & 9.88 & 2006 \\
\hline 3.23 & 91.37 & 12.39 & 2007 \\
\hline 0.61 & 28.51 & 3.50 & متوسط الفترة الأولى \\
\hline 0.92 & 207.05 & 5.68 & 2008 \\
\hline 10.67 & 207.8 & 37.76 & 2009 \\
\hline 9.25 & 164.7 & 27.59 & 2010 \\
\hline 3.14 & 151.17 & 10.28 & 2011 \\
\hline 8.1 & 158.46 & 31.21 & 2012 \\
\hline 2.56 & 127.99 & 9.47 & 2013 \\
\hline 3.62 & 137.07 & 12.65 & 2014 \\
\hline 5.98 & 124.89 & 19.25 & 2015 \\
\hline 4.35 & 159.89 & 16.04 & متوسط الفترة الثانية \\
\hline 613.11 & 460.82 & 358.29 & \% للتغير بين الفترتين \\
\hline
\end{tabular}




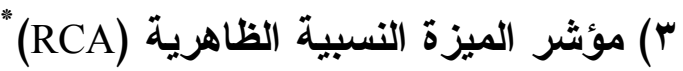

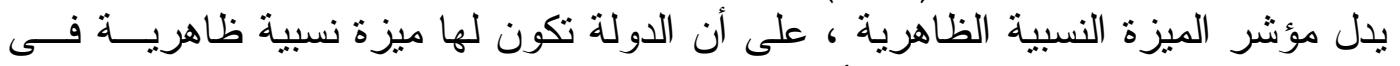

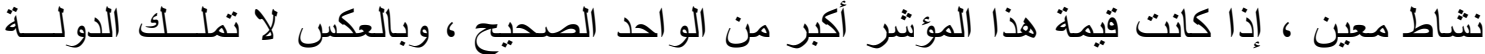

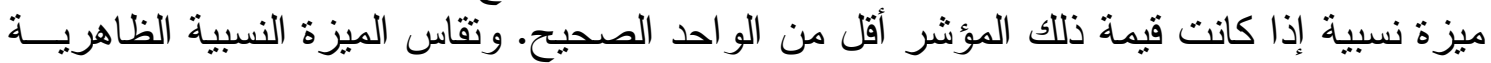

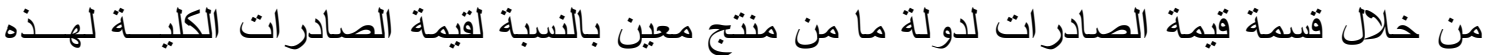

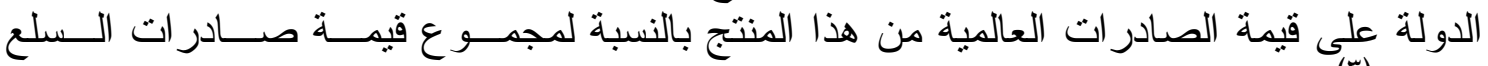

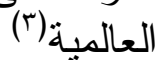

وباستعر اض الجدول رقم (ب): يتضـح أن لجمهورية مصر العربية ميزة نـسبية ظاهريـــة

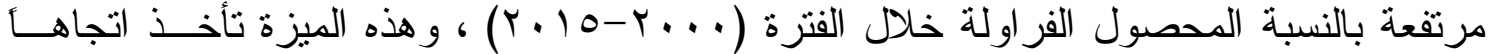

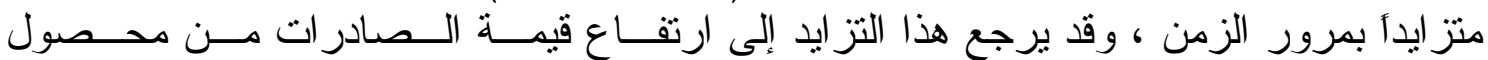

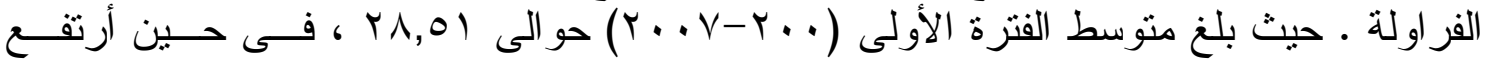

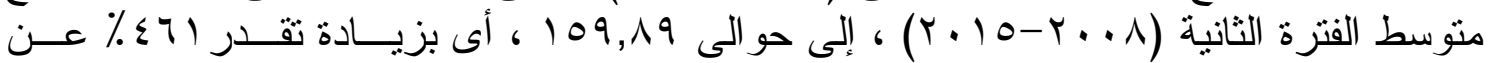

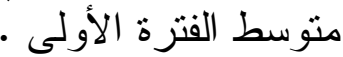
؛ مؤشر الأنصبة السوقية لمصر من الفراولة :

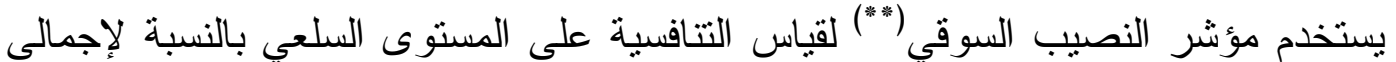

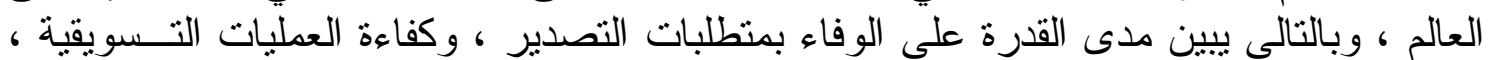

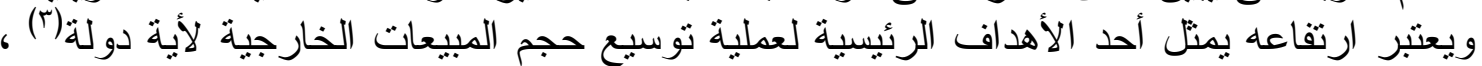

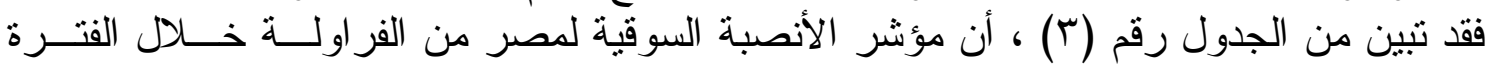

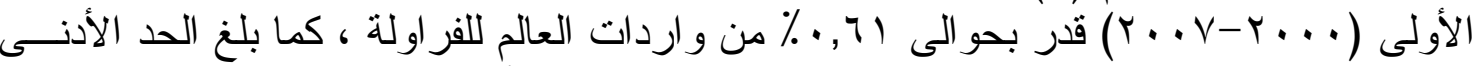

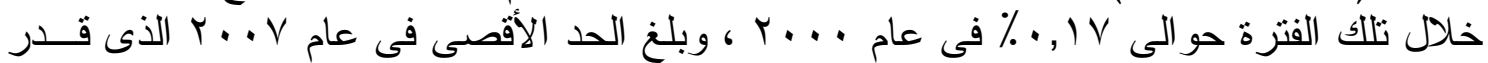

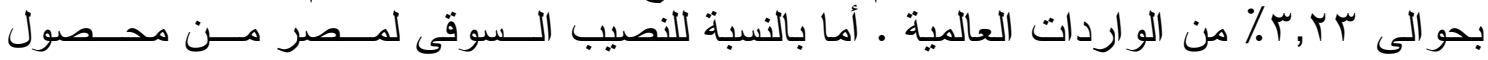

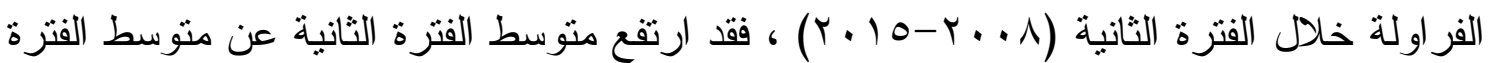

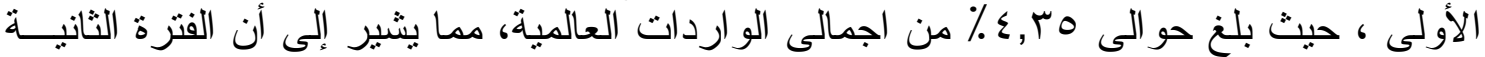

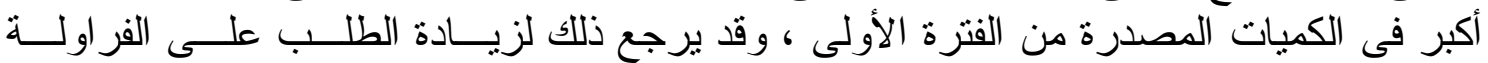

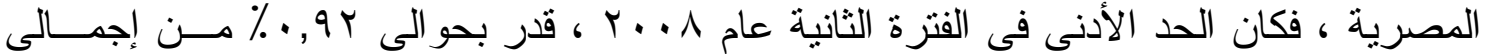

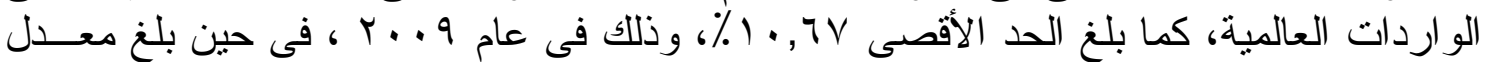

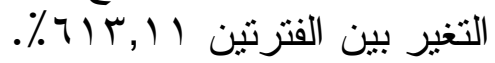

ثالثاً - النموذج القياسي المستخدم في تحديد أهم المتغيرات الاقتصادية المؤثرة علي الكميات

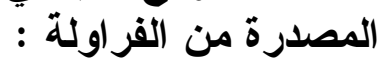

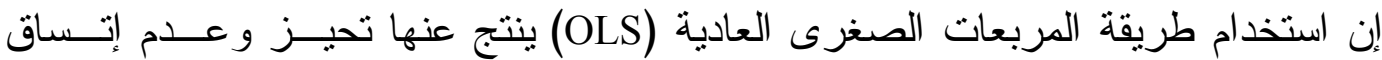

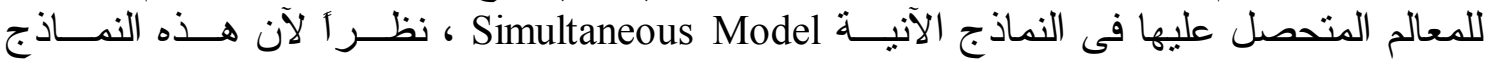

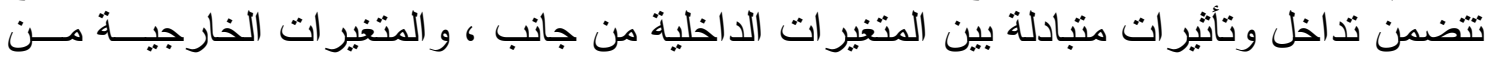

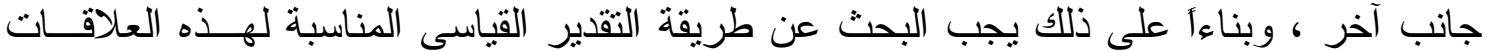
الآنية . آن

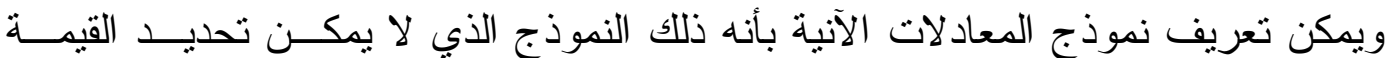

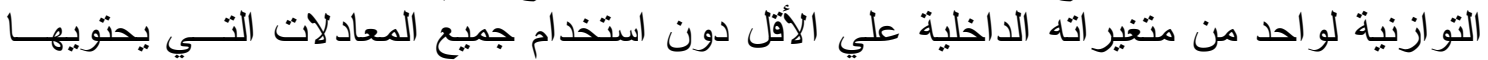

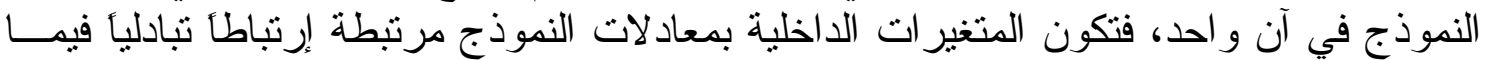

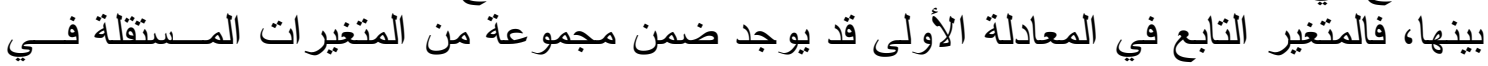

* (RCA) : Revealed Comparative Advantage

* Market Share 


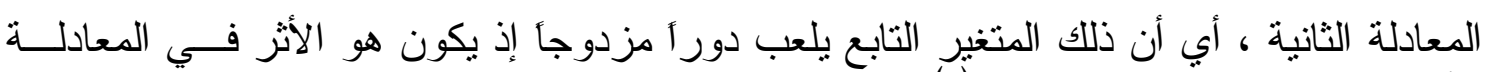

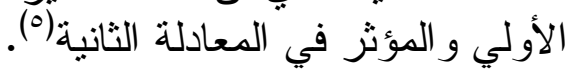

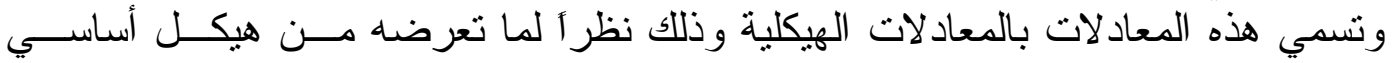

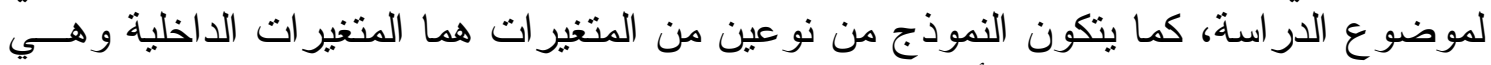

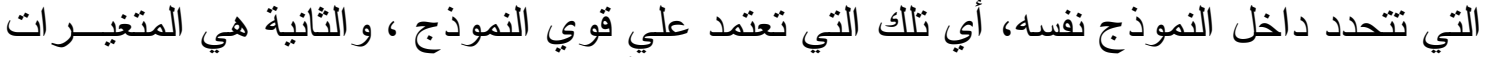

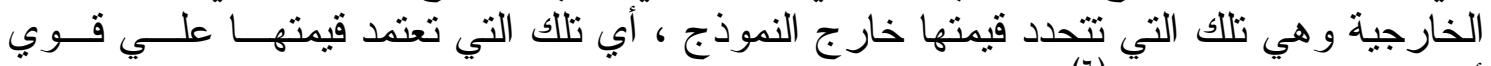

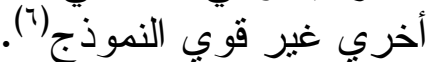

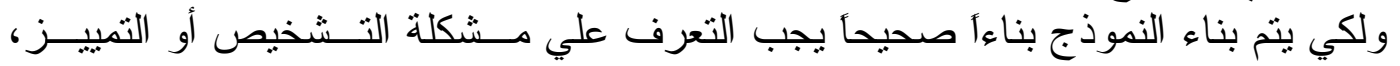

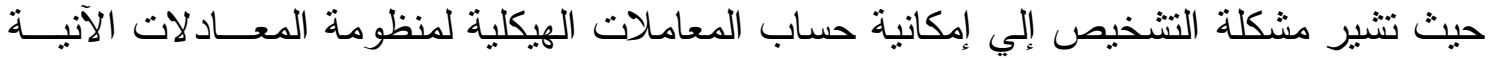

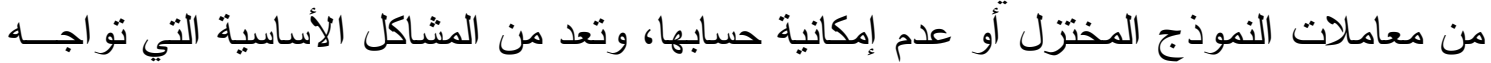

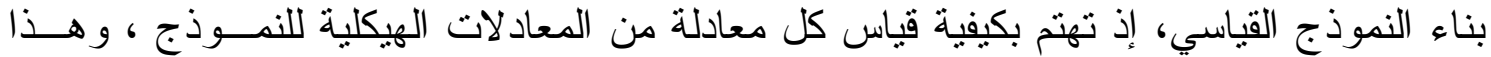

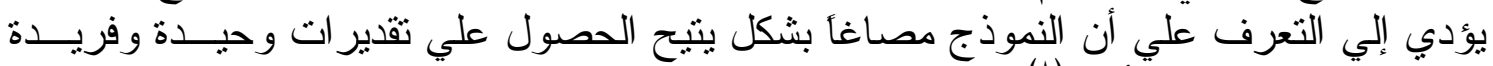

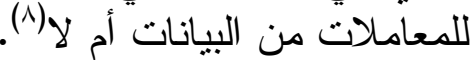

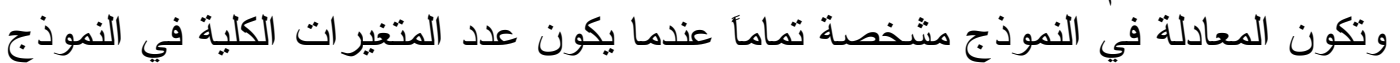

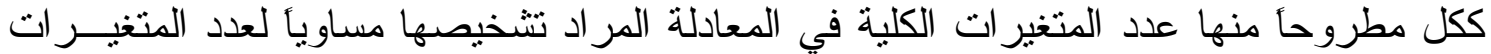

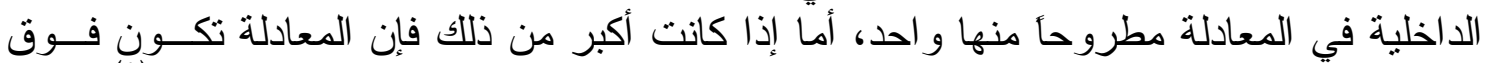

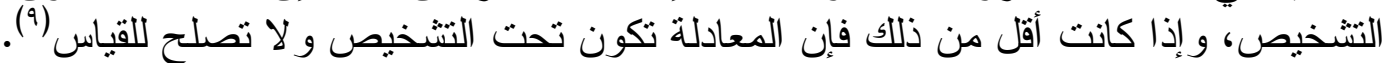

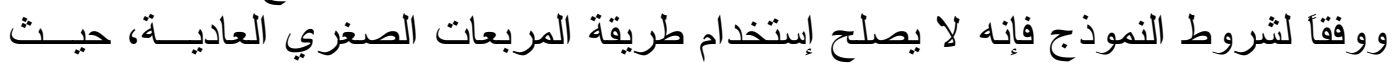

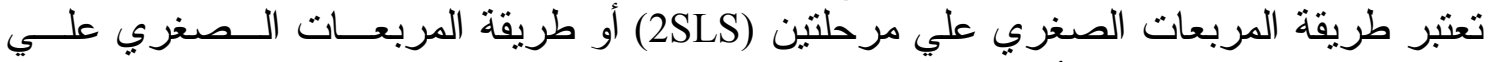

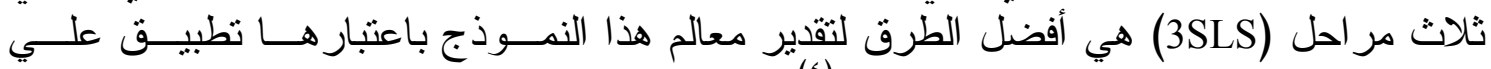

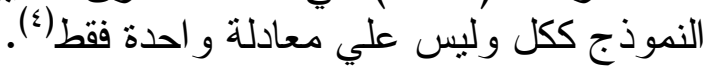

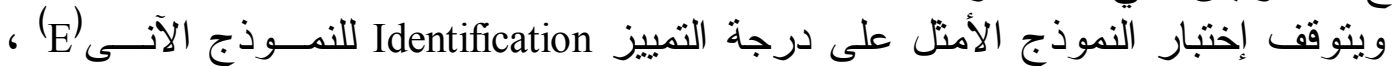

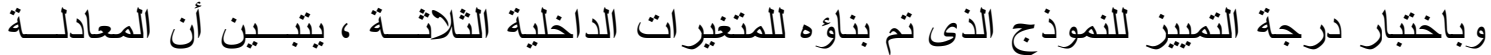

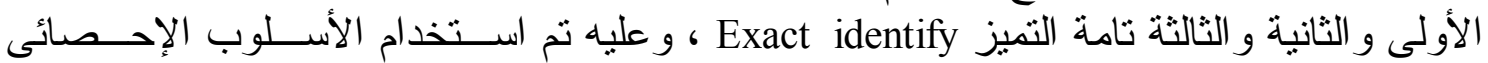

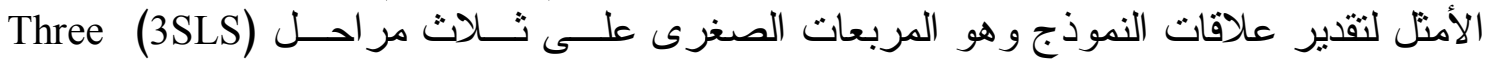
Cochran-Orault Stages Least Squares

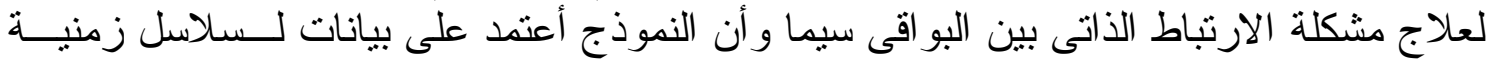

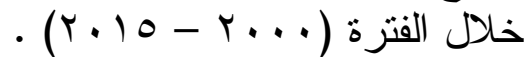

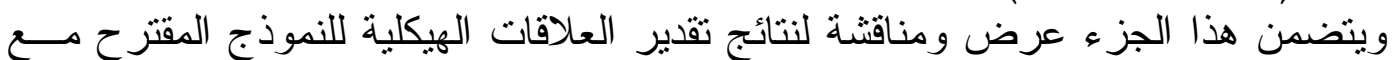

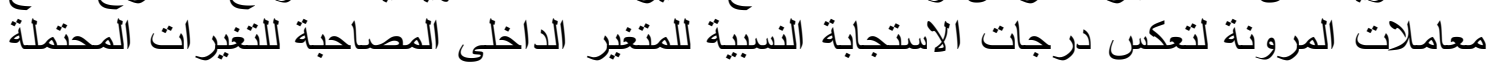

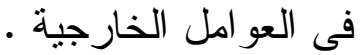
توصيف النموذج :

$$
\begin{aligned}
& \mathbf{Q E t}=\mathbf{C}(\mathbf{1})-\mathbf{C}(2)^{*} \mathbf{Q C t}+\mathbf{C}(3)^{*} \mathbf{T P t}+\mathbf{C}(4) * \mathbf{C A t}+\mathbf{C}(5) * \mathbf{P E P}_{(t-1)} \\
& \mathbf{Q C t}=\mathbf{C}(6)-\mathbf{C}(7) * \mathbf{Q E t}+\mathbf{C}(8) * \mathbf{T P t}+\mathbf{C}(9) * \mathbf{P O P t}+\mathbf{C}(10) * \mathrm{NYGDPt} \\
& T P t=C(11)+C(12) * Q E t+C(13) * Q C t+C(14)^{*} P^{*} P_{(t-1)}+C(15) * T C t
\end{aligned}
$$

$$
\begin{aligned}
& \text { كمية الصادر ات من الفر اولة (ألف طن) } \\
& \text { كمية الاستهالاك من الفر اولة (ألف طن) } \\
& \text { كمية الإنتاج الكلى من الفراولة (ألف طن) }
\end{aligned}
$$

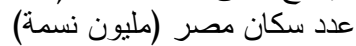

$$
\begin{aligned}
& \text { نصيب الفرد من إجمالي الناتج المحلي (ألف دولار) } \\
& \text { المساحة المزروعة ألف فدان المبان } \\
& \text { سعر التصدير للسنة السابقة دولار/طن (t-1) } \\
& \text { المستوى التكنولوجى (الزمن) }
\end{aligned}
$$

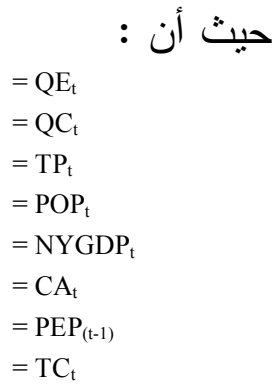




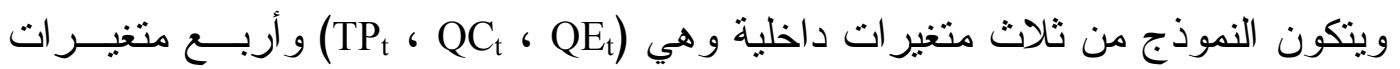

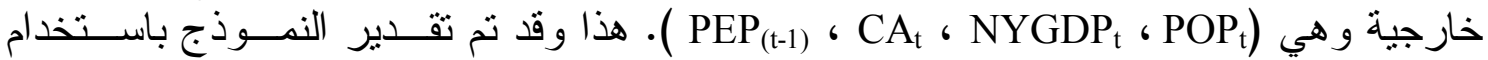

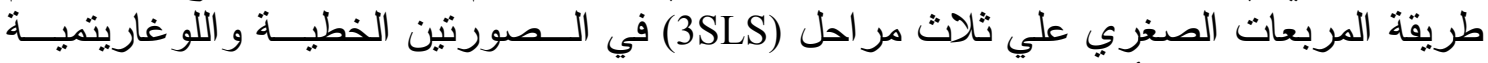

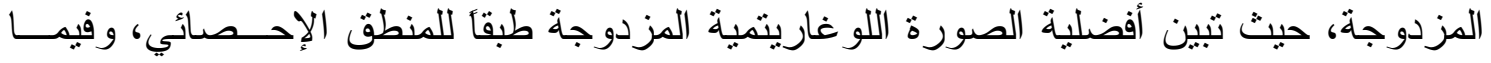

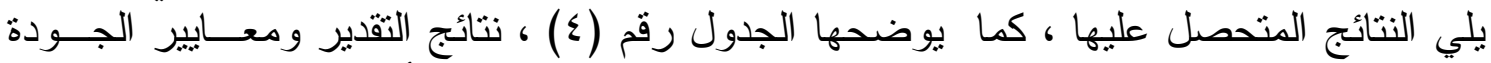

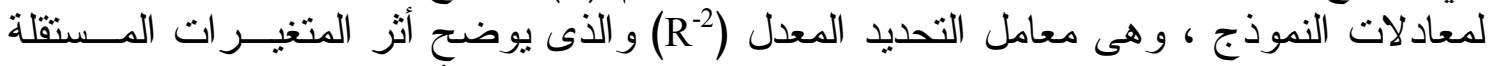

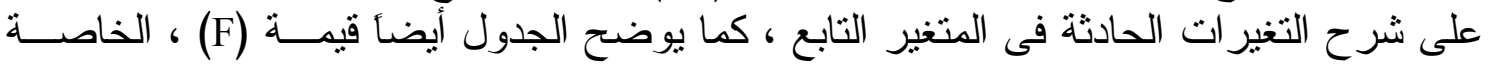

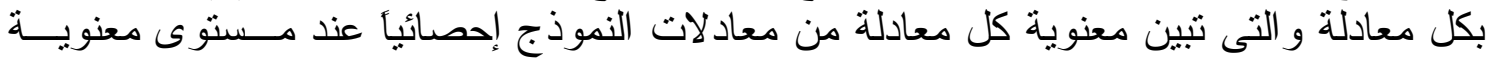

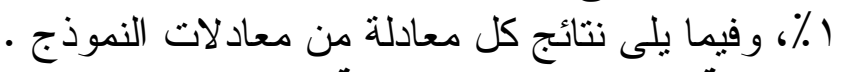

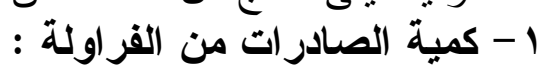

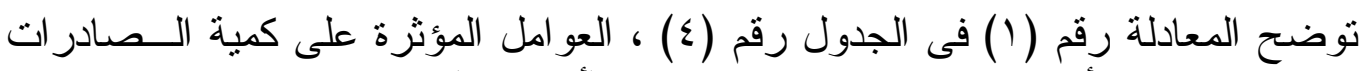

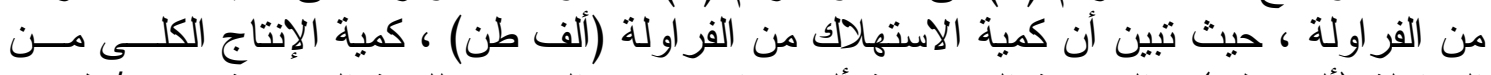

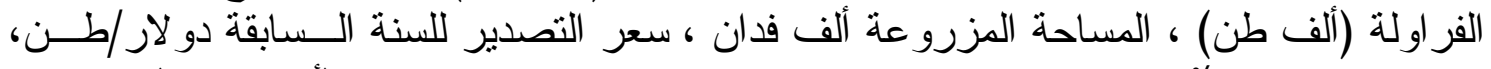

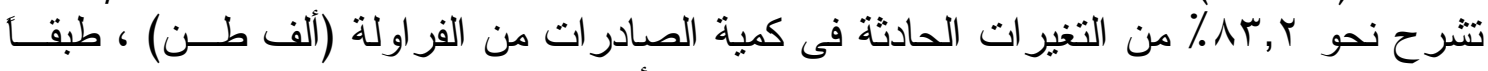

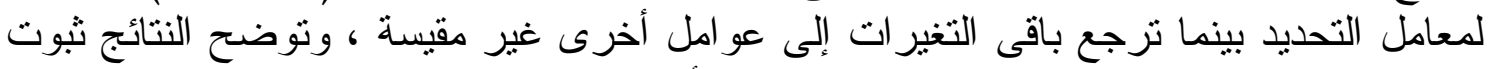

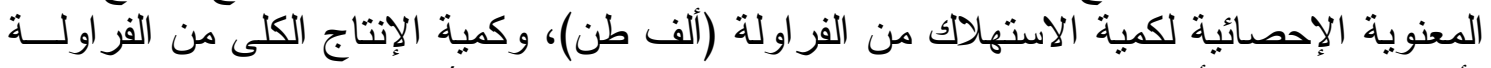

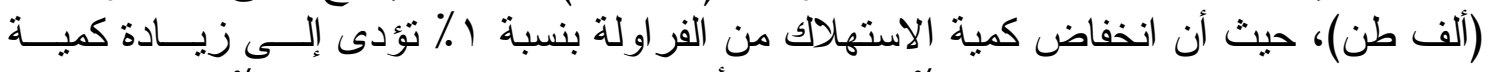

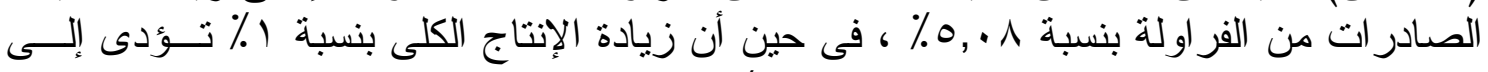

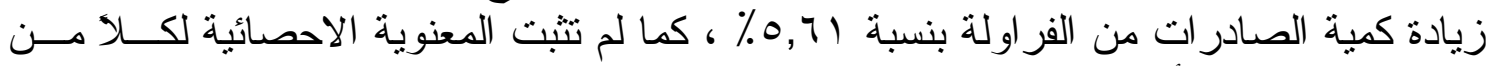
المساحة المزروعة ألف فدان ، سعر التهدئ التصدير للسنة السابقة دو لار /طن.

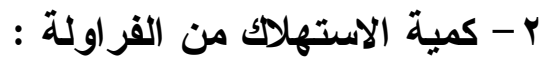

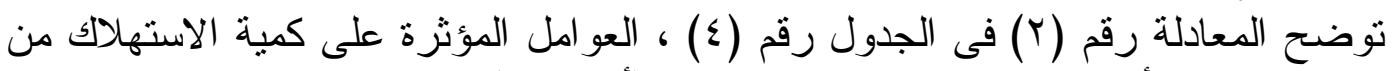

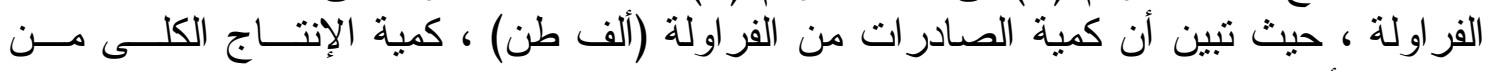

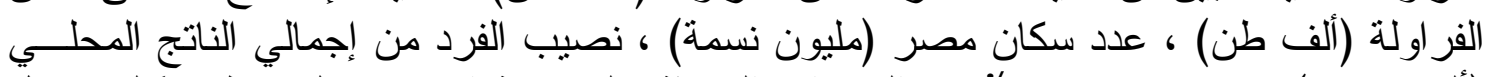

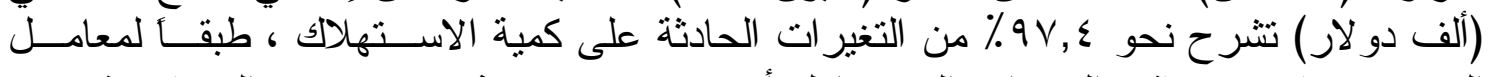

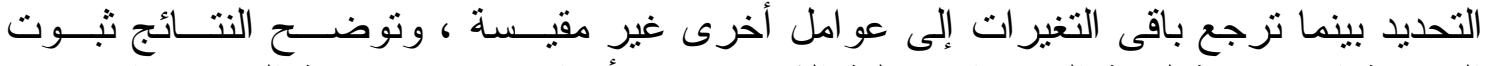

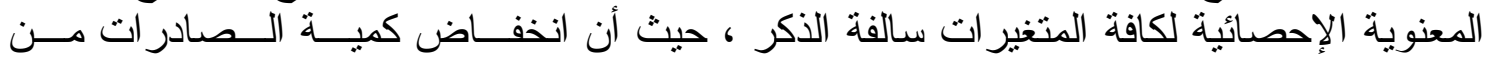

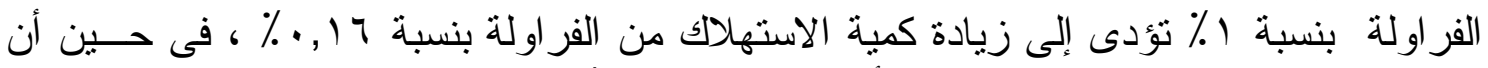

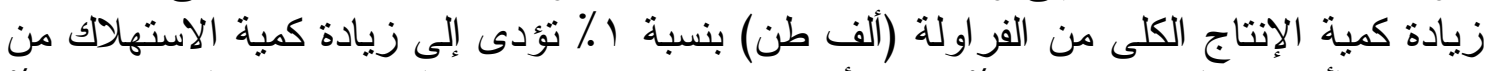

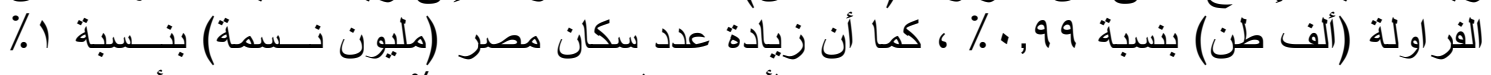

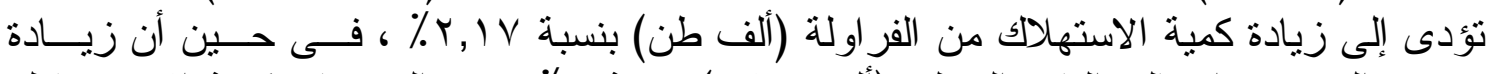

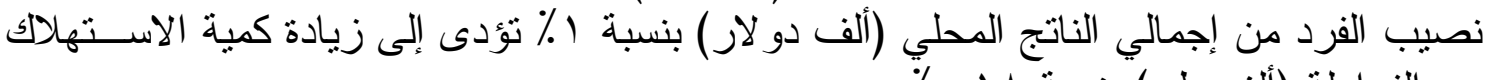

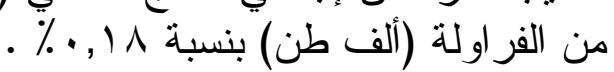




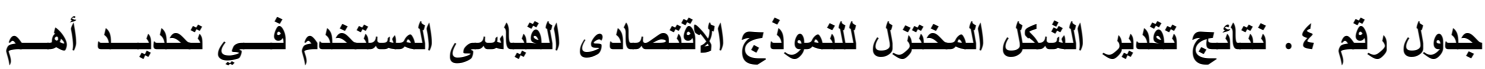

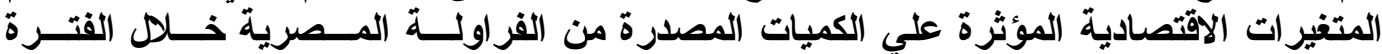

\begin{tabular}{|c|c|c|c|c|c|}
\hline $\begin{array}{l}\text { Durbin- } \\
\text { watson } \\
\text { stat }\end{array}$ & $\mathbf{F}$ & $R^{-2}$ & معادلات النموذج & | المتغير التابع | & 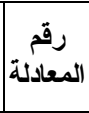 \\
\hline 1.819 & $19.61 * *$ & 0.832 & $\begin{aligned} & \log \mathrm{QEt}=-2.21-5.08 \log \mathrm{QCt}+5.61 \log \mathrm{TPt}+1.07 \log \mathrm{CAt}+0.23 \log \mathrm{PEP}_{(\mathrm{t}-1)} \\
&(-3.03)^{* *}(-5.21)^{* *} \quad(6.20)^{* *} \\
&\end{aligned}$ & |كمية الصادرات & 1 \\
\hline 1.816 & $140.49 * *$ & 0.974 & $\begin{aligned} \log \mathrm{QCt}= & -3.94-0.16 \log \mathrm{QEt}+0.99 \log \mathrm{TPt}+2.17 \log \mathrm{POPt}+0.18 \log \mathrm{NYGDPt} \\
& (-3.89)^{* *}(-7.37)^{* *}(13.89)^{* *}(3.70)^{* *}(2.37)^{*}\end{aligned}$ & |كمية الاستهلاك & 2 \\
\hline 1.920 & $132.25 * *$ & 0.972 & $\begin{aligned} \log \mathrm{TPt}= & 0.24+0.18 \log \mathrm{QEt}+0.90 \log \mathrm{QCt}-0.20 \log \mathrm{PEP}_{(\mathrm{t}-1)}+ \\
& (2.06)^{*}(6.93)^{* *}(13.43)^{* *} \mathrm{Log} \mathrm{TCt} \\
(-0.63) & (2.08)^{*}\end{aligned}$ & كمية الإنتاج & 3 \\
\hline
\end{tabular}

حيث : ( ) القيم الموجودة بين الأقو اس أسفل معاملات الانحدار تشير إلي قيم (t) المحسوبة.

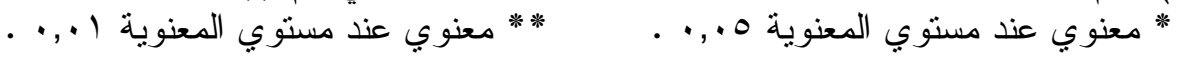

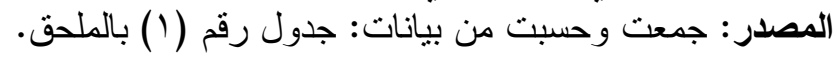

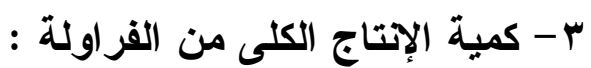

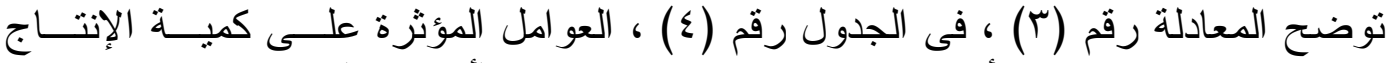

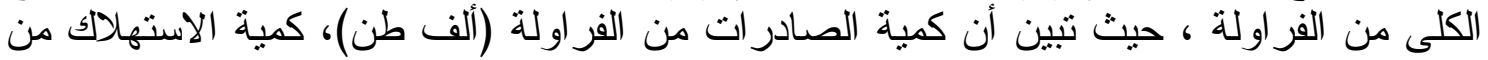

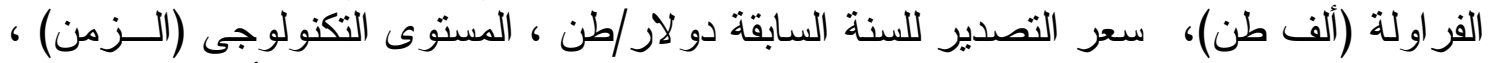

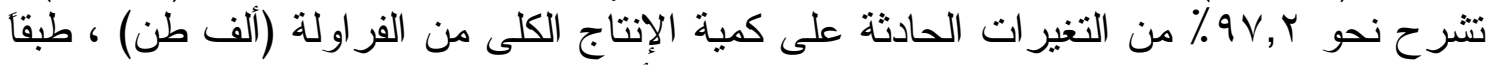

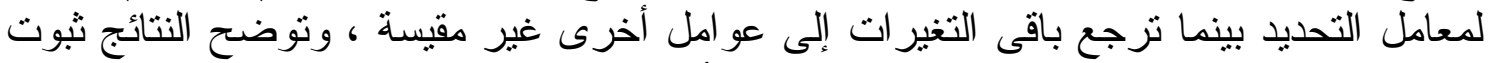

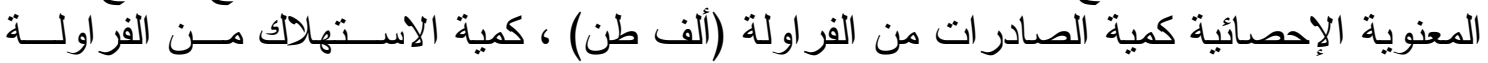

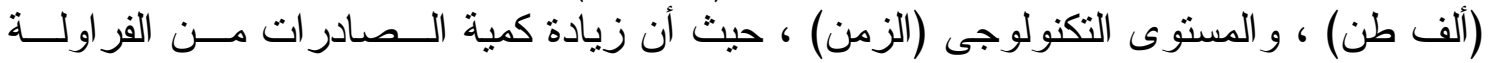

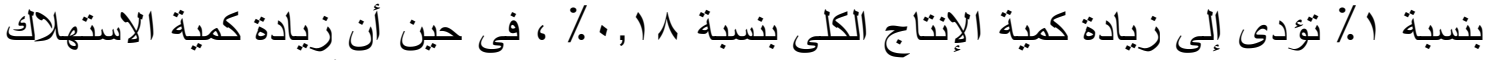

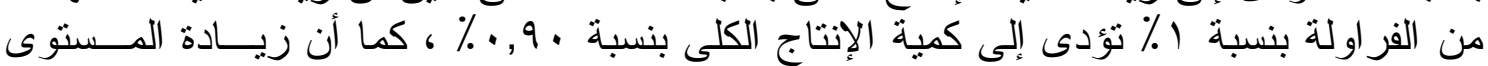

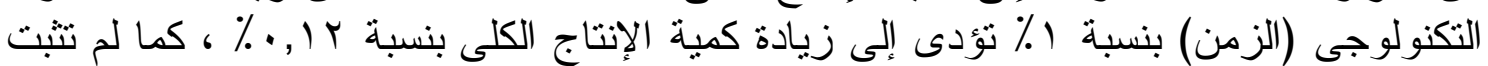

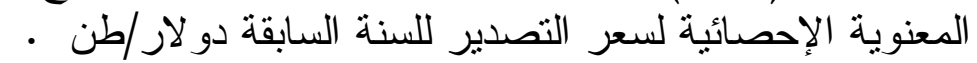

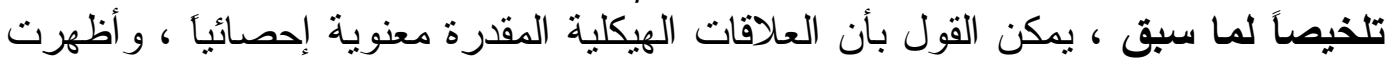

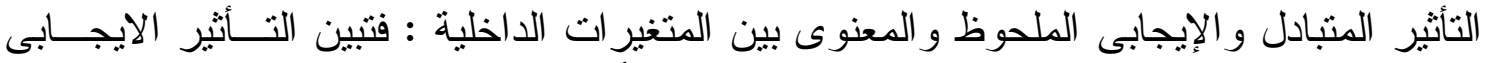

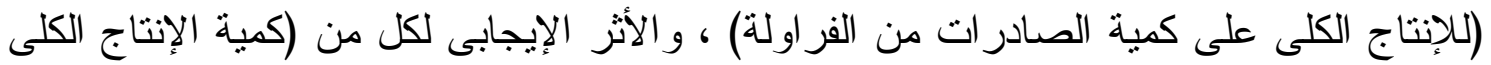

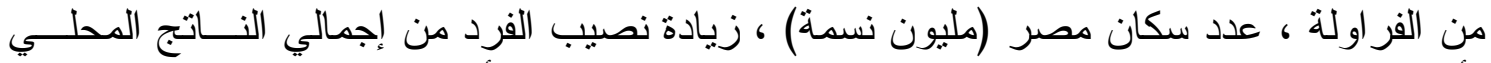

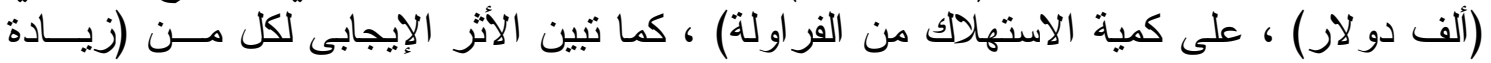

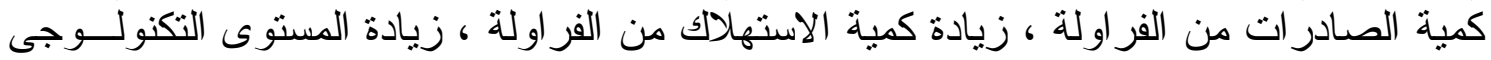

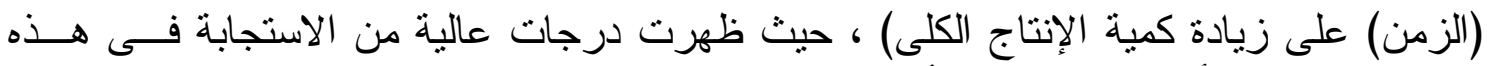

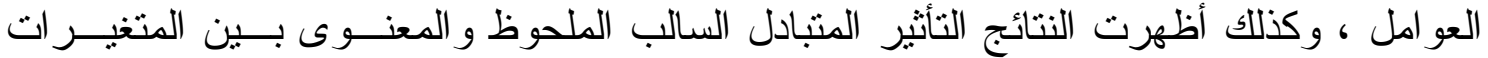

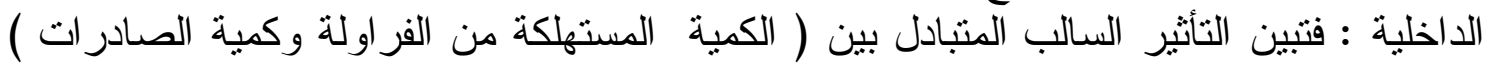

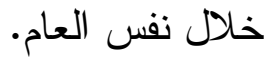
رابعاً - التتبؤ المستقبلى للمتغيرات الهيكلية للنموذج القياسى :

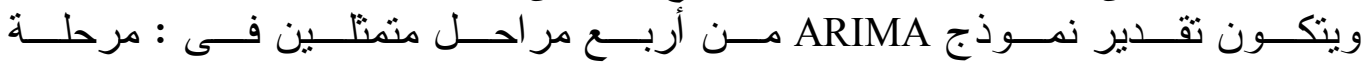

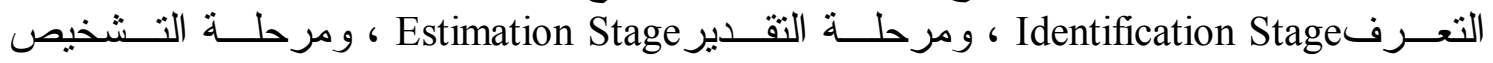

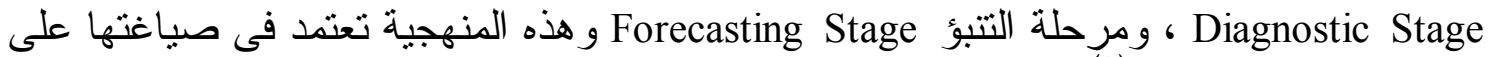

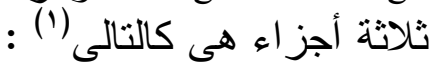




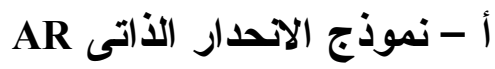

$\mathbf{Y}_{\mathrm{T}}=\mathbf{B}_{0}+\mathbf{B}_{1} \mathbf{Y}_{\mathrm{T}-1}+\mathbf{B}_{2} \mathbf{Y}_{\mathrm{T}-2}+$ $+\mathbf{B}_{\mathrm{P}} \mathbf{Y}_{\mathrm{T}-\mathrm{P}}+\mathbf{e}_{\mathrm{T}}$

(1)

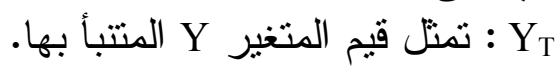
حيث أن:

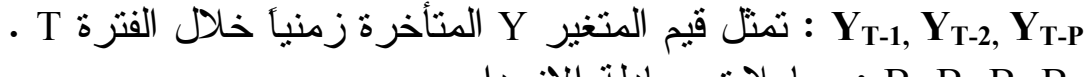
• B B B $_{0}, \mathrm{~B}_{1}, \mathrm{~B}_{2}, \mathrm{~B}_{\mathrm{P}}$ ويثير نموذج الانحدار الذاتى إلى أن القيم الحالية للمتغير Y تعتمد على قيم المتغيــر الـسابقة

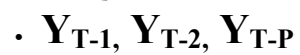

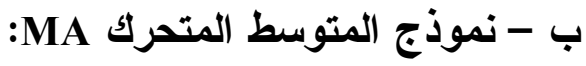
يمكن صباغة نموذج المنوسط المنحر المتحرك بالثكل الآتى : $\mathbf{Y}_{\mathrm{T}}=\mathbf{W}_{0}+\mathbf{e}_{\mathrm{T}}-\mathbf{W}_{1} \mathbf{e}_{\mathrm{T}-1}-\mathbf{W}_{2} \mathbf{e}_{\mathrm{T}-2}+$

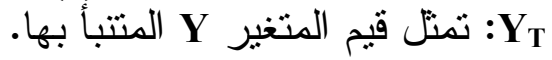

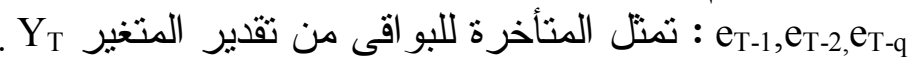
: تمنل الأوزان. ومن : بمنل المتغير العشو ائى. ومن النموذج نجد أن قيم

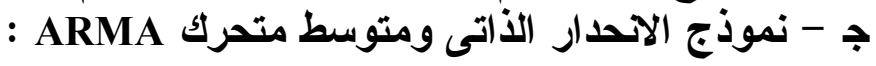

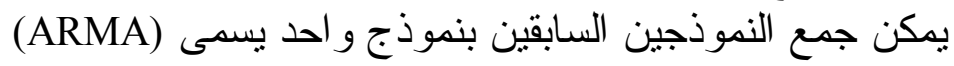
الاثى : Autoregressive integrated moving average $\mathbf{Y}_{\mathrm{T}}=\mathbf{B}_{\mathbf{0}}+\mathbf{B}_{1} \mathbf{Y}_{\mathrm{T}-1}+\mathbf{B}_{2} \mathbf{Y}_{\mathrm{T}-2}+$ $+\mathbf{B}_{\mathrm{P}} \mathbf{Y}_{\mathrm{T}-\mathrm{P}}+\mathbf{e}_{\mathrm{T}}$

$+\mathbf{W}_{0}+\mathbf{e}_{\mathrm{T}}-\mathrm{W}_{1} \mathbf{e}_{\mathrm{T}-1}-\mathrm{W}_{2} \mathbf{e}_{\mathrm{T}-2}+$ $-\mathbf{W}_{\mathbf{q}} \mathbf{e}_{\mathrm{T}-\mathrm{q}}$ الأتى : - n

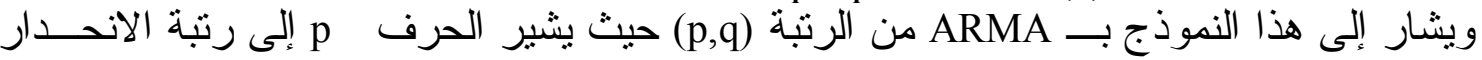

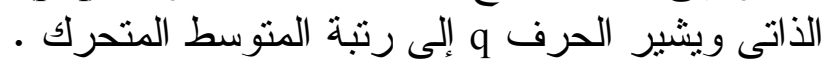
وقبل تطبيق المعادلة السابقة علي بيانات السيط السلسلة الزمنية يجب النيات التأكد من أن هذه السلسلة

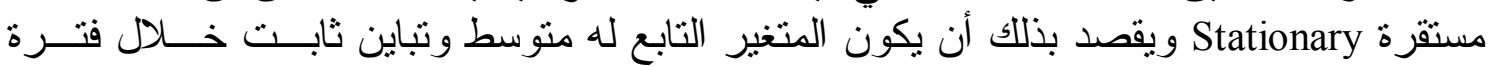

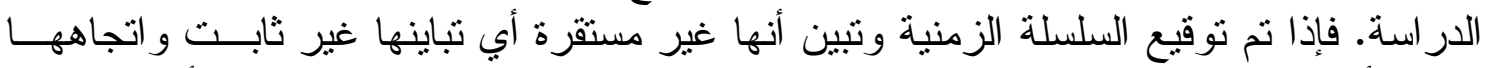

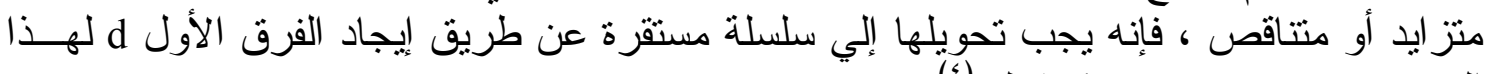

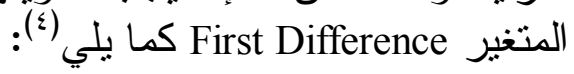
$\mathrm{Y}_{\mathrm{t}}=\Delta \mathrm{Y}=\mathrm{Y}_{\mathrm{t}}-\mathrm{Y}_{\mathrm{t}-1}$

و إذا لم يترتب علي الفرق الأول سلسلة مستقرة يمكن أخذ الفرق الأول لهذا الفرق كما يلي: AY $\mathrm{Y} *_{\mathrm{t}}=\Delta \mathrm{Y}^{*}{ }_{\mathrm{t}}=\mathrm{Y}_{\mathrm{t}}{ }_{\mathrm{t}}-\mathrm{Y}_{\mathrm{t}-1}=\Delta \mathrm{Y}-\mathrm{Yt}_{-1}$

وبصفة عامة يمكن تكر ار عملية الفروق هذه عدة مر ات حتي نحصل علي سلسلة مستقرة:(V)

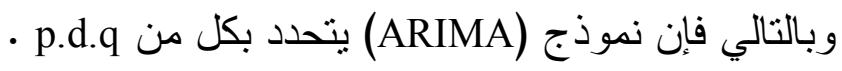

د - التبؤ :

- كمية الصادرات (ألف طن) : وبعد محاو لات متعددة اتضح أن أفضل النماذج هى : $\mathrm{Y}=4.12+1.22 \mathrm{MR}_{(1)}$

$(35.64) * *(5.04) * *$

ويسمى هذا النموذج 


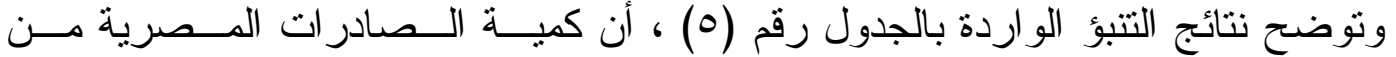

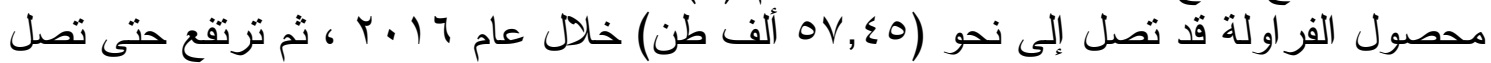

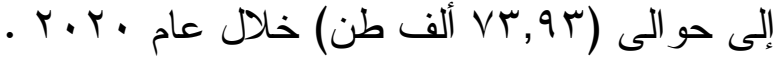

جلول رقم ه. نتائج تتبؤ أفضل النماذج الديناميكية باستخدام نماذج بوكس جنكيز

\begin{tabular}{|c|c|c|c|c|c|c|c|c|c|c|c|}
\hline \multicolumn{4}{|c|}{ الإنتاج الكلى بالإلف طن } & \multicolumn{4}{|c|}{ الاستهلاك ألف طن } & \multicolumn{4}{|c|}{ كمية صادرات الفراولّة ألف طن } \\
\hline اكبر تقليز & أقل تقلير & التتبؤ & السنوات| & اكبر تا & اقل تقلير & التتبؤ & لسنوات & اكبر تقليز & اقل تقليز & التنبؤ & السنوات \\
\hline & & 674 & & & & & & & & & \\
\hline 449. & & 376.7 & & & & & & & & & \\
\hline & & & & & & & & & & & \\
\hline & & & & & & & & & & 69.81 & 2019 \\
\hline 10.39 & 36. & 56.86 & 2020 & 449.17 & 258.04 & 553.60 & & & 31.07 & 33.93 & \\
\hline
\end{tabular}

- كمية الاستهلاك (ألف طن): اتضح أن أفضل النماذج هى :

$\mathrm{Y}=15.88+0.909 \mathrm{MR}_{(1)}$

$(8.54) * *(3.92)^{* * *}$

ويسمى هذا النموذج

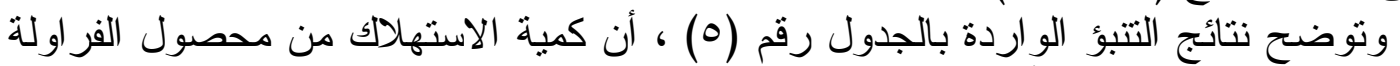

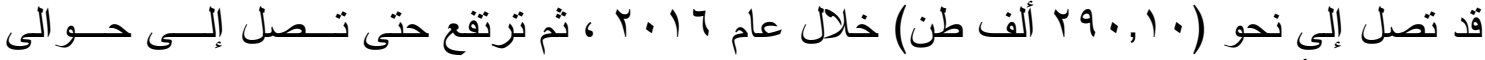

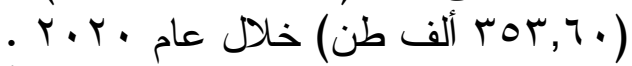
$\mathrm{Y}=20.03+0.902 \mathrm{MR}_{(1)}$ $(12.76) * *(3.05) * *$

ARMA $(0,1,1)$ ويسمى هذا النموذنج

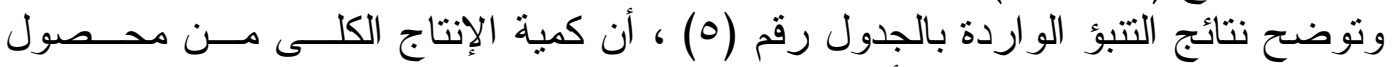

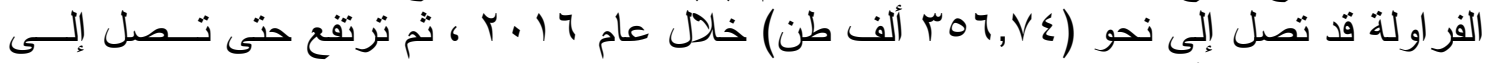

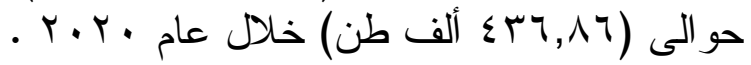

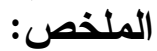

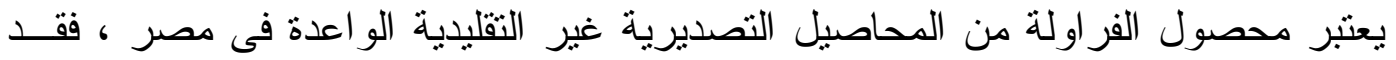

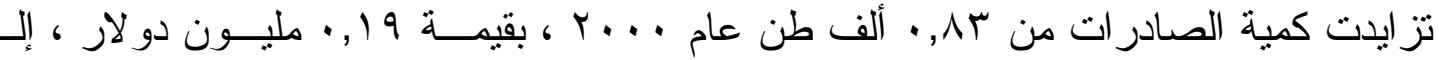

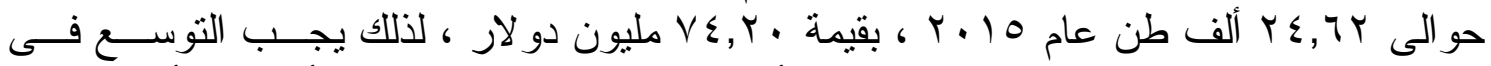

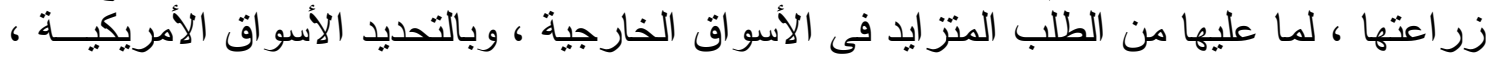

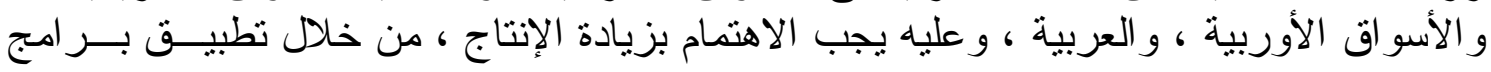

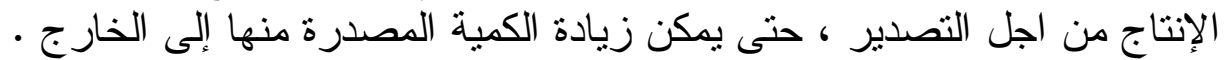

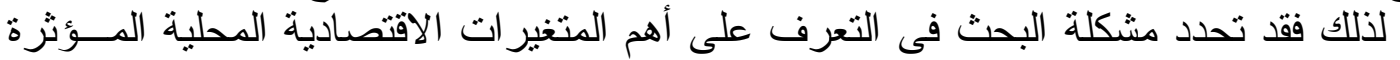

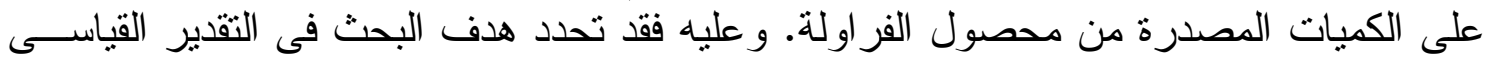

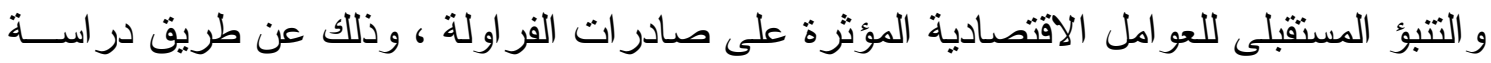

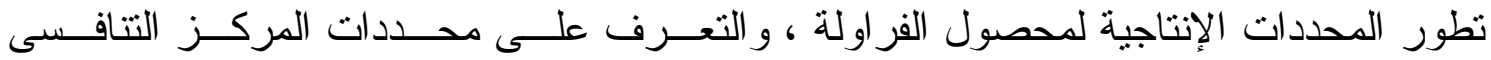

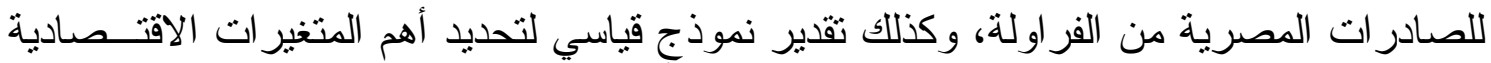

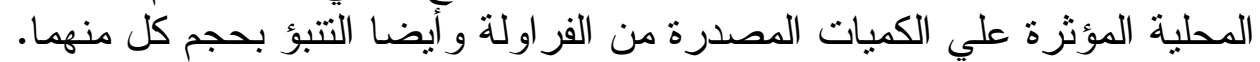

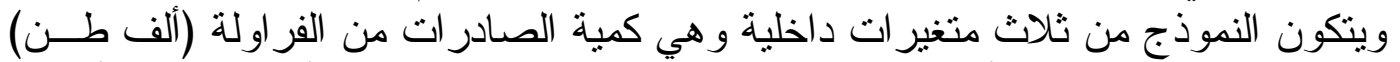

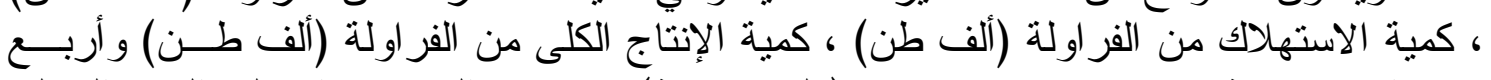
متغير ات خارجية وهي عدد سكان مصر (مليون نسمة) ، نصيب الإني الفرد من إجمالي الناتج المحلي 


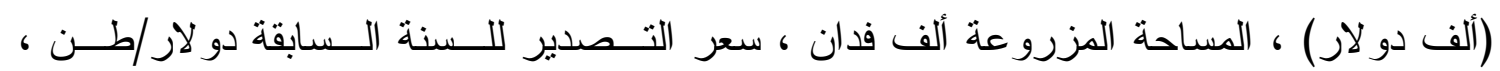

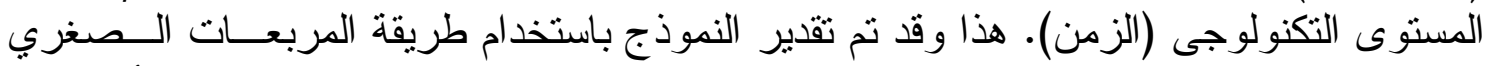

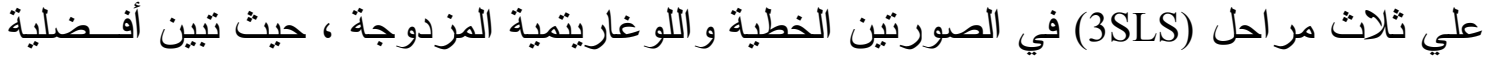

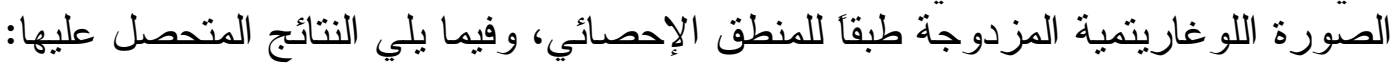

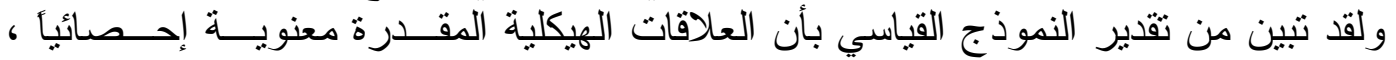

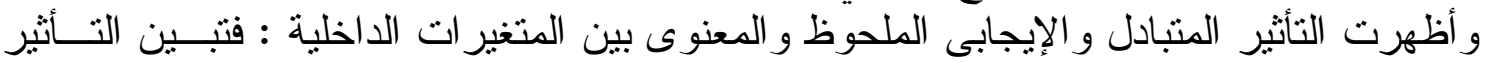

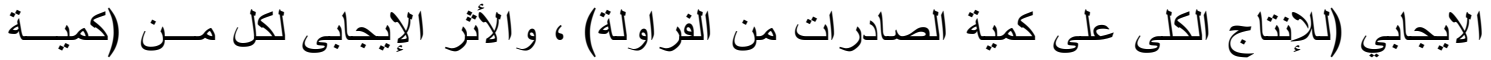

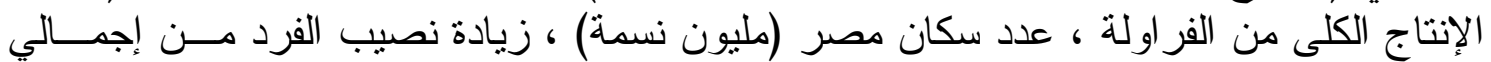

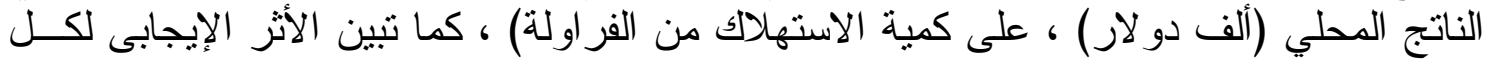

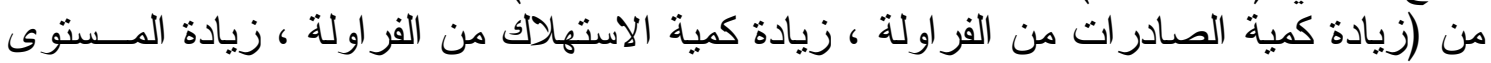

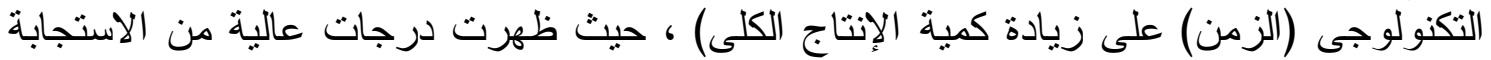

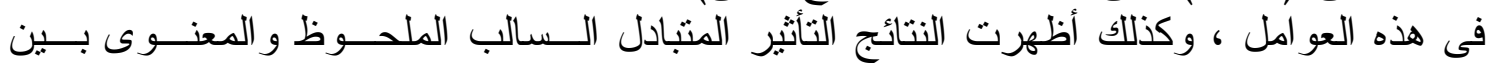

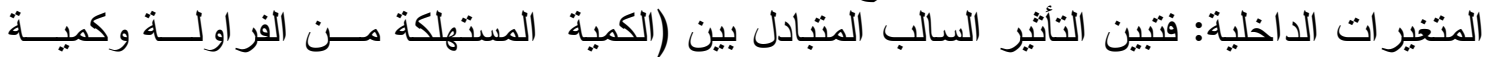

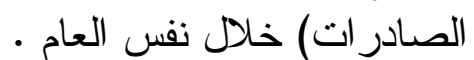

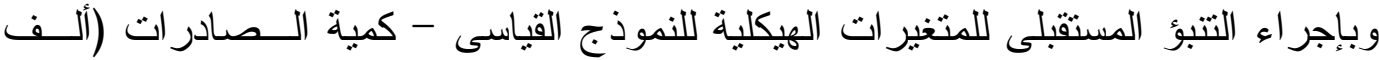

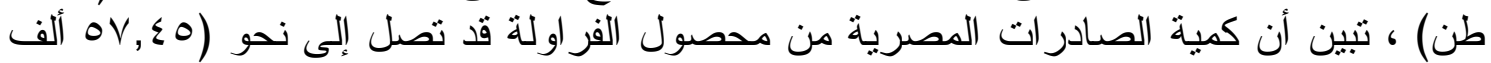

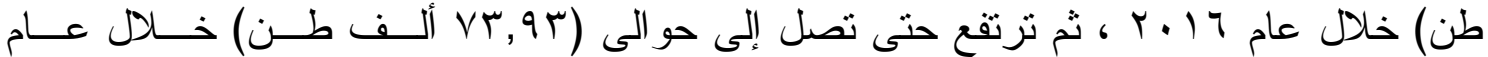

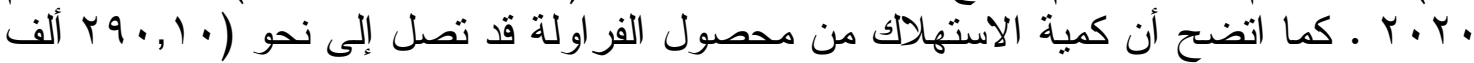

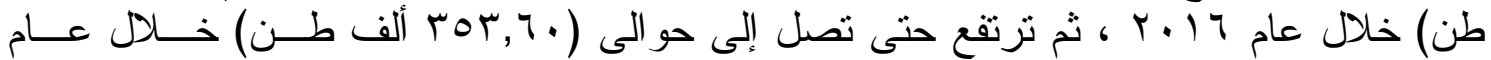

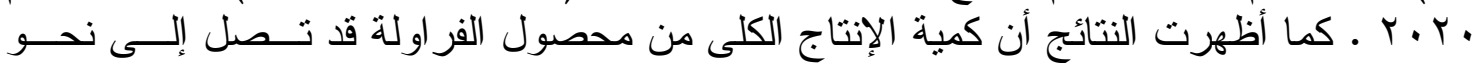

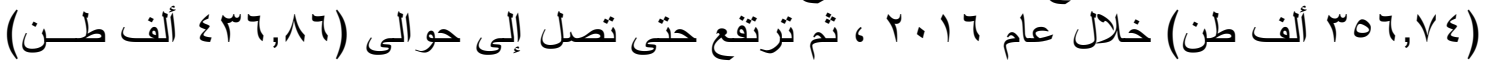

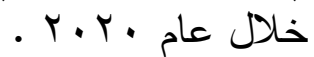

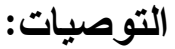
ا. نظر ألأن المز ارع شريك أساسى فى عملية النتمية الزر اعية ، لذلك يجب تدريبه و إرشــاده

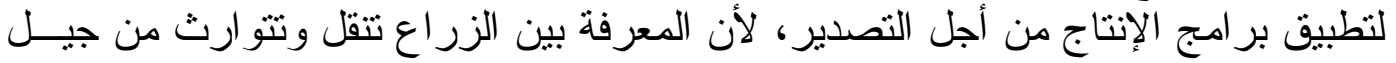

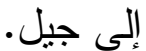

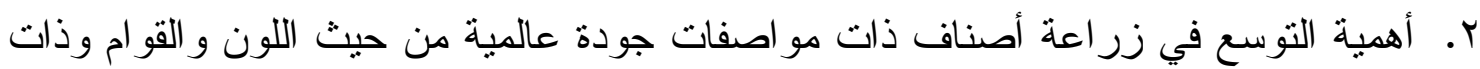

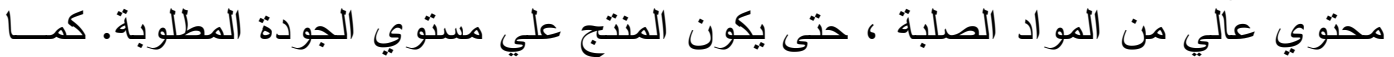

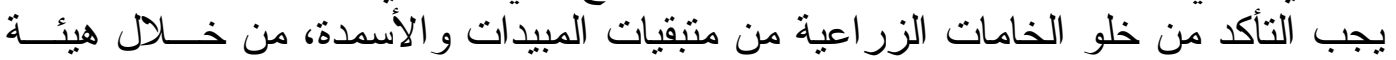
المو اصفات القياسية التابعة لوز ارة التجارة التجارة و الصناعة. r. ضرورة الاهتمام بير امج رفع الإنتاجية الفدانية كأحد أهم عناصر الكاعة الكفاءة الاقتصادية.

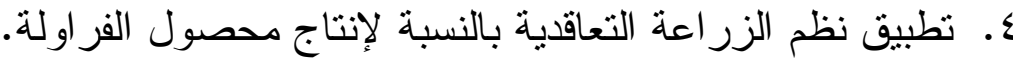

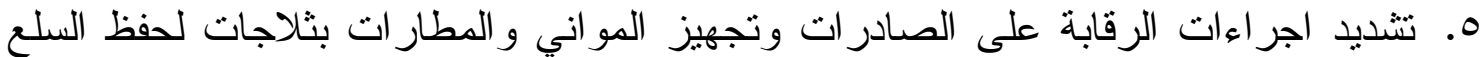
الزر اعية المصدرة و الحرص على على عدم تعرضها للتلف.

ا. أحمد حسين بتال العانى (دكتور) ، استخدام نماذج ARIMA فى النتبؤ الاقتصادى ، ورقة بحثية ،

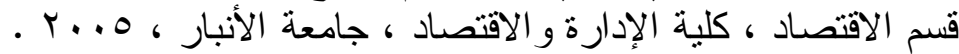

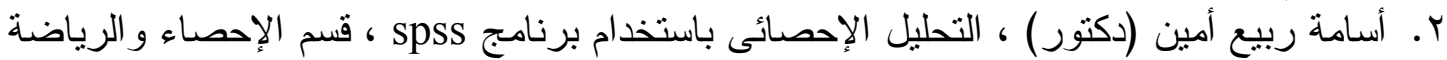
و التأمين ، كلية التجارة بالسادات ، جامعة المنوفية ، مكتبة الأنجلو المصرية. 


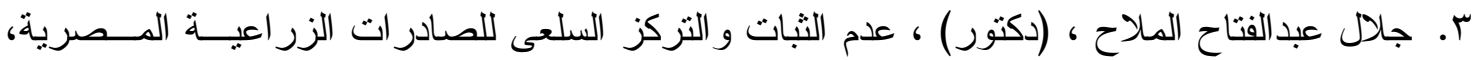

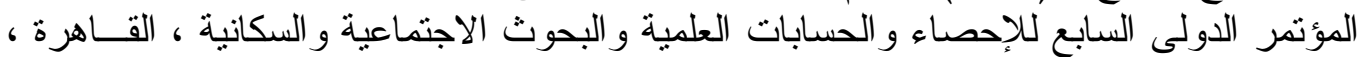

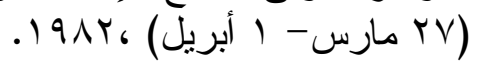

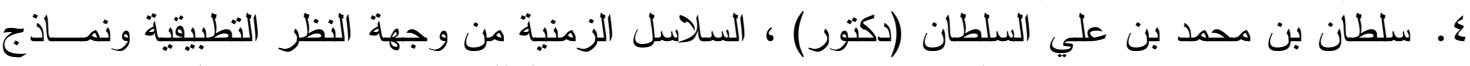

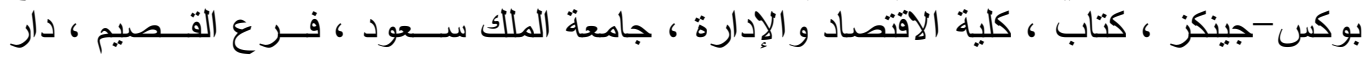

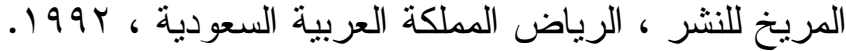

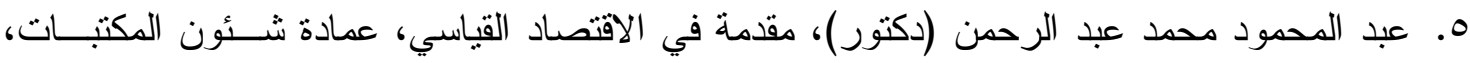

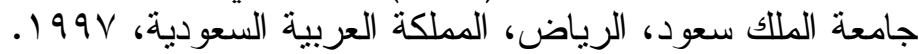

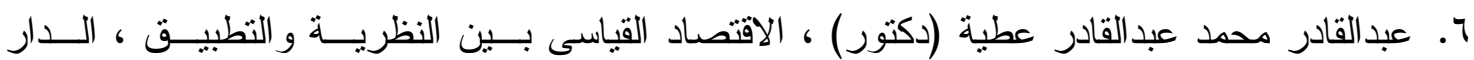

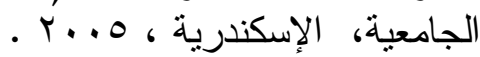

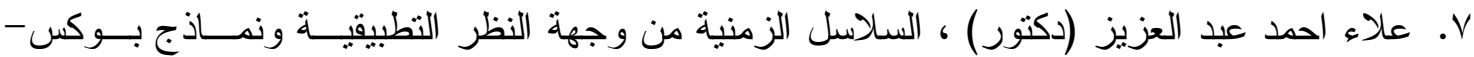

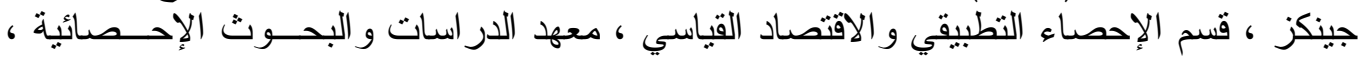

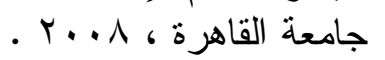

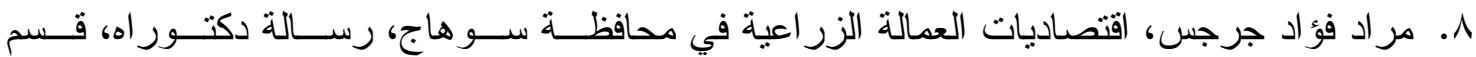

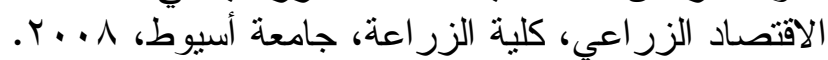

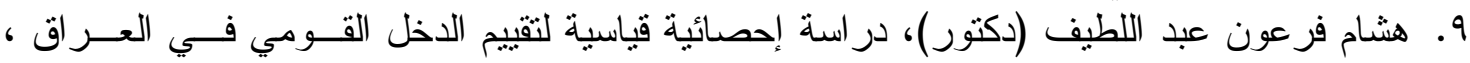

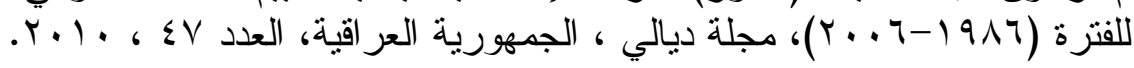

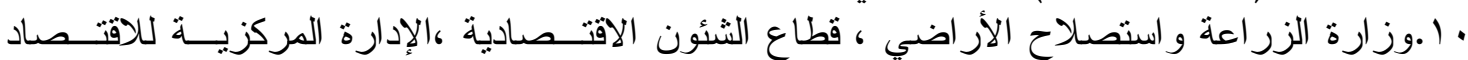

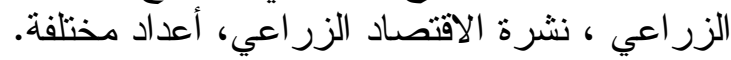

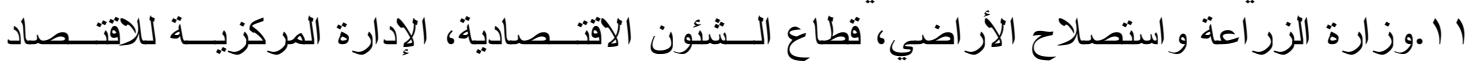
الزر اعي، نشرة الإحصاءات الزاتهات الزر اعية، أعداد مختلفة.

12. Chow, Gregory C. (1988), Econometrics. McGraw- Hill Book Company, Singapore. pp, $342-345$. 


\title{
Standard Analysis and Forecasting The Future of The Economic Factors Affecting Strawberry Exports
}

\author{
Tarek Ali Ahmad Abdullah
}

The Institute of Agricultural Economics Research

\begin{abstract}
The strawberry crop is considerd one of the most promising non-traditional export crops in Egypt. The amount of exports had increased from 0.83 thousand tons in 2000 , with 0.19 million dollars to about 24.62 thousand tons in 2015 , worth 74.20 million dollars soltis important to expand in gloing strowbery, because of the increasing demond in the foreign markets especially the American, European and arab markets. So it's important to give more importance in increasing production through applying product programs for exports in order to increase the exports amount of these strawberry to a brood.
\end{abstract}

\section{The Research Problem}

The research problem may specify the identification of the most local economic variables that affect on the exported amount of strawberry crop.

\section{The Research Aim}

According to the searching problem of the research may specify in studing the development of production determinants of strawberry yield and to identify the determinants of the competitive position of egyption strawberry exports, as well as the estimate of standard model to determine the most important economic variable affecting the export amount of strawberry.

\section{Recommendations:}

1. Since the farmer is a key partner in the agricultural development process, he must be trained and trained to apply production programs for export, because knowledge among farmers is transferred and passed down from generation to generation.

2. The importance of expanding the cultivation of varieties of international quality in terms of color and textures and high content of solids, so that the product to the level of quality required. It is also necessary to ensure that the agricultural raw materials are free of pesticides and fertilizers residues, through the standard specifications of the Ministry of Commerce and Industry.

3. The need to pay attention to programs to raise productivity as one of the most important elements of economic efficiency.

4. Application of contractual farming systems for strawberry production.

5. Strict export control measures and the processing of ports and airports with refrigerators for the preservation of exported agricultural commodities and ensure that they are not damaged. 


\section{الملحق}

جدول رقم 1 ـ تطور أهم المتغيرات الاقتصادية المؤثرة على صادرات مصر من الفراولة خلا الفتــرة

\section{$(r+10-r \ldots)$}

\begin{tabular}{|c|c|c|c|c|c|c|c|c|c|c|c|c|c|}
\hline |قليمة صادرات الزيوراتية & قصيمة صلزدراتية & العليمة صن الثراداتلة & التصدير & 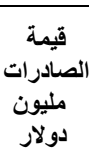 & ألف طراولة & (اللف طن) & 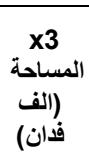 & 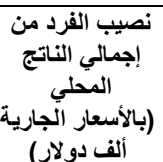 & ملميرن & $\mid$ & |إلقنتاجية & |بالألفاولة & الس - الس \\
\hline 7334703 & 8. & 681.12 & 8.92 & 0.19 & 0.83 & 9.78 & 6.40 & 1.461 & 68.33 & 70.61 & 1.03 & 6.40 & 2000 \\
\hline 7081976 & 530 & & 258.06 & 0.32 & 1.24 & 66.9 & 6.43 & 1.403 & 69.6 & 68.14 & 10.60 & 6.43 & 200 \\
\hline & & & 392.07 & 0.89 & 2.27 & 57.75 & 5.76 & 1.2 & & 60.02 & 10.43 & 76 & \\
\hline 8700 & & & 521.28 & 1.47 & 2.82 & 76.95 & 7.31 & 1.1 & 2.25 & \begin{tabular}{|l|l|}
79.77 \\
\end{tabular} & 10.91 & 7.31 & 2003 \\
\hline 10593 & 12 & 08.47 & 616.28 & 2.12 & 3.44 & 101.53 & 9.13 & 1.071 & 73.6 & 104.97 & 11.49 & 9.13 & 2004 \\
\hline & & & 570. & 1.74 & 3.05 & 104.2 & 12. & & 74. & & 13.01 & & \\
\hline 1383 & & & 500.79 & 6.35 & 12.68 & 115.67 & 10. & 1.409 & 76.2 & 128.35 & 2.58 & 10.20 & 200 \\
\hline 1587 & & & 557.15 & 12.04 & 21.61 & 152 & 15. & & 77. & & & & \\
\hline 1816 & & & 690.69 & 52.23 & 75.62 & 129.09 & 12. & 2.062 & 78.98 & & 16.07 & 2.46 & 2008 \\
\hline 1435 & 3383 & 17 & 1291.39 & 86.51 & 66.99 & 164.66 & 13. & 2.3 & 80.44 & 242.78 & 17.69 & .72 & 2009 \\
\hline & & & 2671.97 & 65.49 & 24.51 & 146. & & & 82.04 & & & & 10 \\
\hline 2093 & & & 783.14 & 58.72 & 74.98 & 165.3 & 13. & 2.817 & 83.79 & & 17.93 & 40 & 2011 \\
\hline & & & 3363.83 & 77.20 & 2295 & 212.75 & & & & & 745 & & \\
\hline & & & 2092.14 & 69.48 & 33.21 & 20 & & & & & & & \\
\hline 21723 & 4938.94 & 242 & 1378.63 & 75.48 & 54.75 & 229.62 & 15.5 & 3.366 & 89.58 & 284.37 & 18.35 & 15.50 & 201 \\
\hline \begin{tabular}{|l|}
18949220 \\
\end{tabular} & 4699.97 & 2395.46 & 3013.81 & 74.20 & 24.62 & 410.72 & 22.88 & 3.615 & 91.51 & 435.3 & 19.03 & 22.88 & 201 \\
\hline
\end{tabular}

ا. ال. موقع وز ارة التتمية الاقتصادية www.op.gov.eg ، مؤشر ات اقتصادية . r. . الجهاز المركزي للتعبئة العامة والإحصاء، الكتاب الإحصائي السنوي، نثرات التجارة الخارجية، القاهرة، أعداد متفرقة. /http:/www.worldbank.org r. موقع البنك الدولى 